\title{
B. TRIANGULATION
}

\author{
Compiled by E. M. Douglas
}

\section{GENERAL CONDITIONS FOR MAP CONTROL}

The boundary lines of all regular United States Geological Survey maps are parallels of latitude and meridians of longitude. In order that these shall be properly located and that intermediate points shall be placed in correct positions, some system of horizontal control is required. The method to be adopted for linear control should be fixed by the character of the country, one of the requirements being that all control work shall be so accurate that no errors will be apparent in maps several times as large in scale as those to be published. In mountainous regions or in hilly, partly timbered areas horizontal control is effected by a system of triangulation, the whole area being divided into triangles whose apexes are represented by stations established on prominent points several miles apart. The angles between each station and all others visible from it are carefully measured with a theodolite graduated to read angles by micrometer to two seconds of arc or by estimation to fifths of a second. One side of the triangles, called the base line, must be carefully measured with a steel tape, if its length has not been previously determined, account being taken of slope of the line, elevation above sea level, temperature of the tape, and other essential details; and for at least one station the exact latitude and longitude and also the azimuth of one of the lines leading from the station must be determined by astronomic observations or by a connection with stations previously located.

In heavily timbered areas, where it is difficult to see from any point more than a mile or two in any direction, horizontal control is best obtained from distances measured on the ground with a 300foot steel tape, a record being made of angles measured with a transit at each bend in the line. Such control, called transit traverse, must begin and end at points whose positions have been previously determined, and regardless of the character of the country such control must be carried around the edge of each quadrangle and once across its center east and west.

Because of the great expense involved in base-line measurements and in the determination of positions from astronomic observations, 
it is generally advisable to connect triangulation systems or traverse lines with positions previously determined, even though they may be a long distance away. There are now few localities in the United States that can not conveniently be connected with known positions, and therefore, before horizontal control work is begun, the records of the Coast and Geodetic Survey, the Lake Survey, the United States Army Engineers, and other Government organizations should be examined in order to ascertain what positions in or near the area to be surveyed have been determined and are available for use in the work in hand.

Wherever possible, geographic locations should be based on the North American datum (formerly known as the United States standard datum), for there is in many localities a considerable differerence between the standard and astronomic data.

The results of triangulation or transit traverse by the Geological Survey can always be obtained by anyone having occasion to use them by applying to the Director, United States Geological Survey, Washington, D. C.

The United States Board of Surveys and Maps has fixed requirements for triangulation control, from which geographic positions are to be computed, as follows:

\begin{tabular}{|c|c|c|c|}
\hline & $\begin{array}{l}\text { First } \\
\text { order }\end{array}$ & $\begin{array}{c}\text { Second } \\
\text { order }\end{array}$ & $\begin{array}{l}\text { Third } \\
\text { order }\end{array}$ \\
\hline $\begin{array}{l}\text { A verage triangle closure } \\
\text { Check on base.......... }\end{array}$ & $1: 25,000$ & $1: 10,000$ & $\begin{array}{r}5 \\
1: 5,000\end{array}$ \\
\hline
\end{tabular}

Triangulation by the Geological Survey as described on the following pages, which is intended for map control only, is classed by the Board of Surveys and Maps as of the "third order," consequently the triangles should close with an average error of not more than 5 seconds, and the check on the terminal line or base must not exceed 1 part in 5,000 of the length of the line. Triangulation of the two higher orders serves both for geodetic investigations and for map control. At present such work is carried on by the United States Coast and Geodetic Survey in accordance with special instructions prepared by that bureau.

\section{TRIANGULATION FIELD WORK.}

\section{GENERAL REQUIREMENTS}

Amount of control.-At least three serviceable stations of the third or a higher order must be established for each quadrangle, regardless of the scale of the map, and as many more as may be necessary to afford adequate bases for plane-table control. In addition, a number of secondary points-such as church spires, windmills, water tanks, 
trees, and in high mountain regions some of the more prominent summits-must be located by intersection and checked by angles from one or more stations or by the "three-point method," which gives satisfactory results if a fourth point is sighted for a check. Where no such objects are available, at least two points should be flagged for intersection if practicable. These points are intended to afford supplemental control for the topographer and should be selected with special reference to their usefulness in that connection.

The triangulator is also expected to locate, when practicable, either by direct measurement from his stations or by the three-point method, conspicuous objects, marks on State and county boundary lines, and township and section corners. Especial attention should be given to township and section corners because of their recognized value in the control of the land-line net. The General Land Office will on request addressed to the Washington office detail a cadastral engineer to assist in finding and identifying corners of the public-land surveys.

Selection of stations.- Stations should be selected and signals built before any observing is done, and to this end the triangulator and his assistant should make a reconnaissance over the area to be controlled. This reconnaissance should be thorough enough to disclose every practical scheme of triangulation and the angles at each point should be measured with a prismatic compass and platted with the protractor so that the size and proportions of the figures may be ascertained. All preparatory work, such as setting tablets and posts, erecting signals and scaffolds, clearing lines of sight, and obtaining consent of the owner, if on private land, should be completed during this reconnaissance, so that the final observing may be performed with economy and dispatch. The reconnaissance affords the triangulator opportunity to acquaint himself with the shortest routes of travel, the best stopping places, the available camp sites, water holes, pastures, and trails, and the best routes for scaling each peak to be occupied; and it enables him to gain a familiarity with the special character of each station and its signal which will be invaluable to him in identifying the points when he sights them later on. Each station must be named, and as station names are to be published, efforts should be made to select those which have local significance. The name selected should be stamped into the metal station mark with steel dies.

Figures.-The most desirable groups of triangles consist of either quadrilaterals with both diagonals sighted or central-point figures with four to seven sides. The triangles composing these figures should be well proportioned, angles measuring not less than $30^{\circ}$ nor more than $120^{\circ}$ each. The scheme should not be allowed to dwindle down to single, unsupported triangles, and especial care should be taken to connect the work done with other work by means 
of well-proportioned triangles. Overlapping figures or an excess of observed lines beyond those necessary to insure a double determination of each length are undesirable, although a diagonal through some figure may occasionally be valuable as a check. As a rule additional lines of this kind only complicate the main scheme without materially adding to its strength, and the numerous observations made for them are discarded by the computers as superfluous. Judgment is to be used in this matter, however, for in many regions the atmospheric conditions are exceedingly uncertain, and the observer can not always count on being able to see in both directions over every line that may be essential to the main scheme. In such regions it is well to err on the safe side and obtain too many data rather than too few.

Angles should be read to all prominent points outside of the area for use in future expansion, even though the points lack signals or are not sharply defined.

Secondary points.-In cutting in secondary points for topographic control it should be remembered that locations that depend on two sights only, even if the angles are of adequate size, are likely to be of doubtful value, because of the absence of any check on possible gross errors in observing or computing, or because of the possibility of mistakes in the identification of the points. An endeavor should therefore be made to obtain at least three sights to every secondary point, even if the triangles are not of the best shape. Observers are especially cautioned not to slight the location of secondary points merely because they happen to be of no importance in their scheme of figures. As the topographer may find it expedient to start his control from a secondary point, a blunder in the location of such a point may result in his starting with an erroneous base and having later to make corrections at a great cost.

Consent of owner.-Before a site for a station on private land is selected, the written consent of the owner should be obtained, if practicable, for establishing a permanent station mark and erecting the" required signal. If a summit must be cleared of timber, or if lines of sight must be cut, the value of the timber to be cut should be definitely fixed and agreed upon with the owner before cutting is begun.

When it is necessary to clear away timber and the owner or agent for the ground can not be reached without great delay, three residents of the locality should be asked to appraise the value of the timber cut and to sign a written statement regarding it. This statement should be forwarded to the office of the Survey for consideration if a claim for damage is filed.

Station marks.-Triangulation stations must be permanently marked by standard bench-mark tablets, each tablet to be set in 
rock in place or in the top of a concrete or stone pier. (See pl. 4 and also p. 120 of leveling instructions, for instructions in regard to setting tablets.) When practicable, bottles or other imperishable material should be left as subsurface marks.

Two or more permanent reference marks should be established about each station mark. These may consist of holes drilled in rock in place in which a metal reference mark tablet is to be fixed, with the arrow pointing toward the station; spikes in roots of trees; or large stones set solidly in the ground. The azimuth and the distance to each reference mark must be duly entered in the field record.

When old stations are revisited and any of the marks are found to be defective or to have been destroyed, new marks must be established in their places, and a report regarding them must be sent at once to the Washington office.

Signals.-Triangulation signals must be built with a view to their permanence as well as to their visibility. They may be of various forms, the form selected depending on the locality and the materials at hand. Thus, a signal on a bare mountain peak may be a rock cairn; one on a partly wooded summit may be a straight tree, the surrounding timber being cleared away; one on cleared land may be a tripod or quadripod. (See pl. 1.)

Rock cairns should be not less than 8 feet high and should be well put together, so that they will withstand strong winds and heavy snows. A pole or a small green tree placed in the top is of advantage in sighting.

Signal trees are most satisfactory if stripped of their branches, except a tuft at the top. They form the best of targets when sighted against the sky, but if they are to be sighted against a dark background, they should carry two triangular targets 3 to 6 feet on a side, placed at right angles to each other and covered with white cloth.

Tripods or quadripods should be built of sawed lumber if such matcrial is available. For the legs and center pole 2 by 4 inch scantlings may be used; for the cross braces 1 by 6 inch boards. The base of the pyramid should be large enough to permit a theodolite to be set up under the center pole. In order to increase its visibility, boards may be nailed across the sides about a foot apart and covered with signal cloth, and cross targets may be attached to the center pole above the apex of the pyramid. The best colors for this cloth are white and black or white and red.

Most signals stand in exposed places and should be securely anchored to prevent their being blown over. The legs of tripods and quadripods should be placed in the ground at least 2 feet; each leg should be fastened to a "deadman" and the hole filled with thoroughly tamped earth or rocks, or else a stake 4 feet long should be driven into the ground at an angle with each leg and firmly spiked 
to it. If the ground is too rocky to permit the digging of holes, a 4-foot crosspiece should be nailed to each leg at right angles flat on the ground and weighted down with rocks. Signals built on solid rock should be fastened to ring bolts leaded or wedged in holes drilled in the rock.

Observing towers.-High observing towers (pl. 1) should be avoided wherever possible, but where local conditions make them necessary provision should be made for determining the azimuth from the tower to some point visible from the ground. If no permanent object is visible, an azimuth mark should be set at least 500 feet distant and its direction determined, with at least one check observation. A description of the azimuth mark in sufficient detail to make its identification certain should be recorded. The distance to the mark from the station, either measured or estimated, should be stated. If it becomes necessary to elevate the instrument, a scaffold must be erected in the form of a tripod, capped with a thick board 12 inches square to support the instrument. Around this scaffold, but entirely independent of it, should be built another, in quadripod form supporting a platform on which the observer is to stand. If very high such a scaffold should be composed of successive bents, each 8 or 12 feet, with diagonal bracing. The outer scaffold is to serve also as a signal and for that purpose should extend at least 6 feet above the observing platform and be surmounted by a mast bearing cross targets. Before fixing signals in position the direction in which sights are to be taken should be carefully ascertained, so that no woodwork will. interfere with the observations.

The size of the timbers to be used necessarily depends on the height of the structure. The amount of lumber required may be determined by means of a rough drawing of the structure to scale.

Centering of signals.-Signals should stand over station marks wherever possible, so as to avoid the necessity of computing swings for the angles. Great care must be taken to insure perfect centering of signal and scaffold over the station mark, a plumb bob being used for this purpose.

If centering the signal is impracticable, as it is with a tree signal, the distance and bearing of the signal to the station mark must be carefully measured and recorded.

The permanent mark, tablet, or concrete post must always be considered the station for which the geodetic position will later be computed, and when observations are made for angles the theodolite should be set up over its center if possible. If it is impracticable to center the instrument over the station mark, the distance between the point occupied and the station mark must be carefully measured and recorded. One or more sets of angles must also be read between the station mark and the other stations, in order of azimuth, preferably with the $0^{\circ} 0^{\prime} 00^{\prime \prime}$ for the pointing to the station mark. 


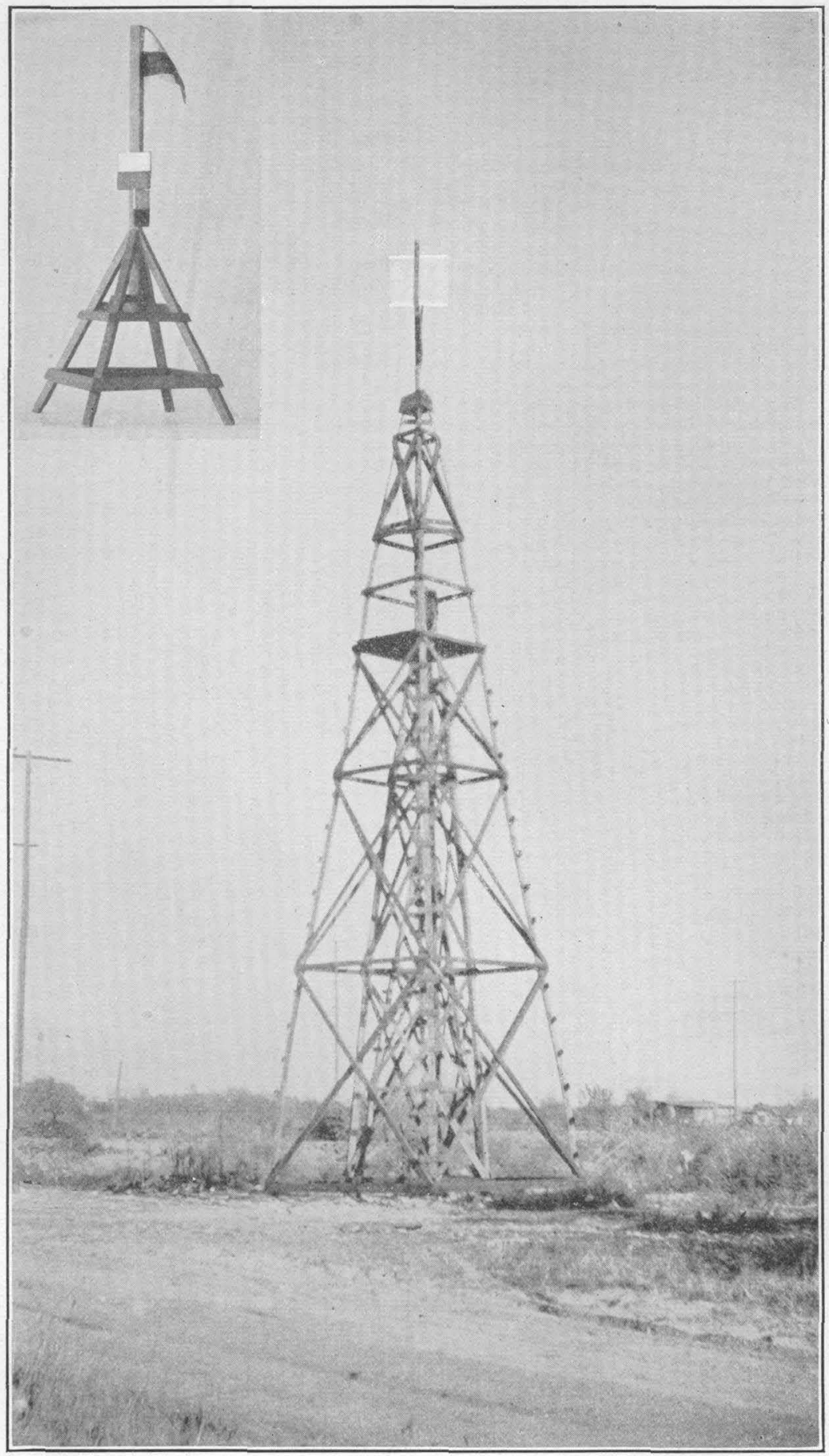

OBSERVING TOWER AND SIGNALS 


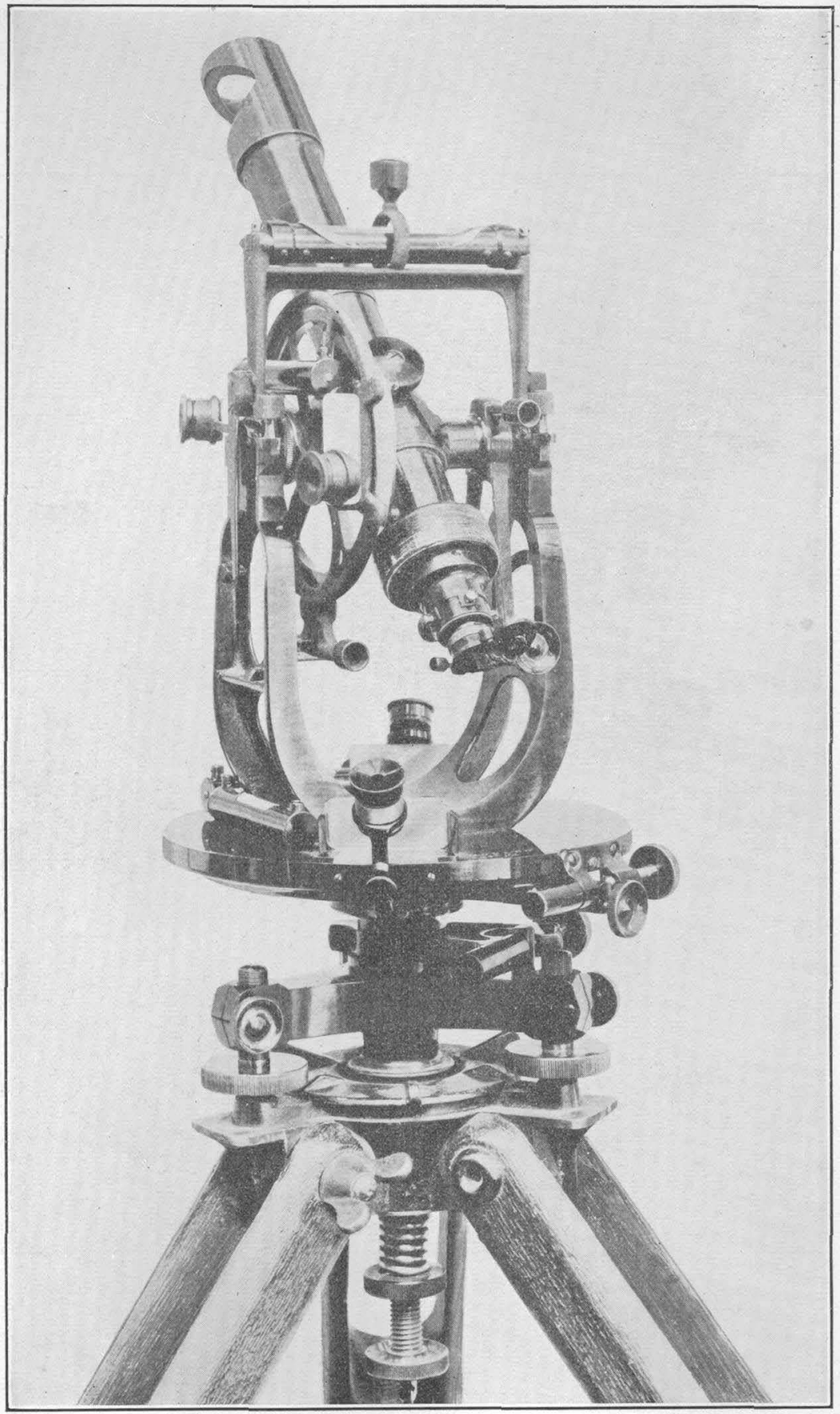

VERNIER TRANSIT-THEODOLITE 


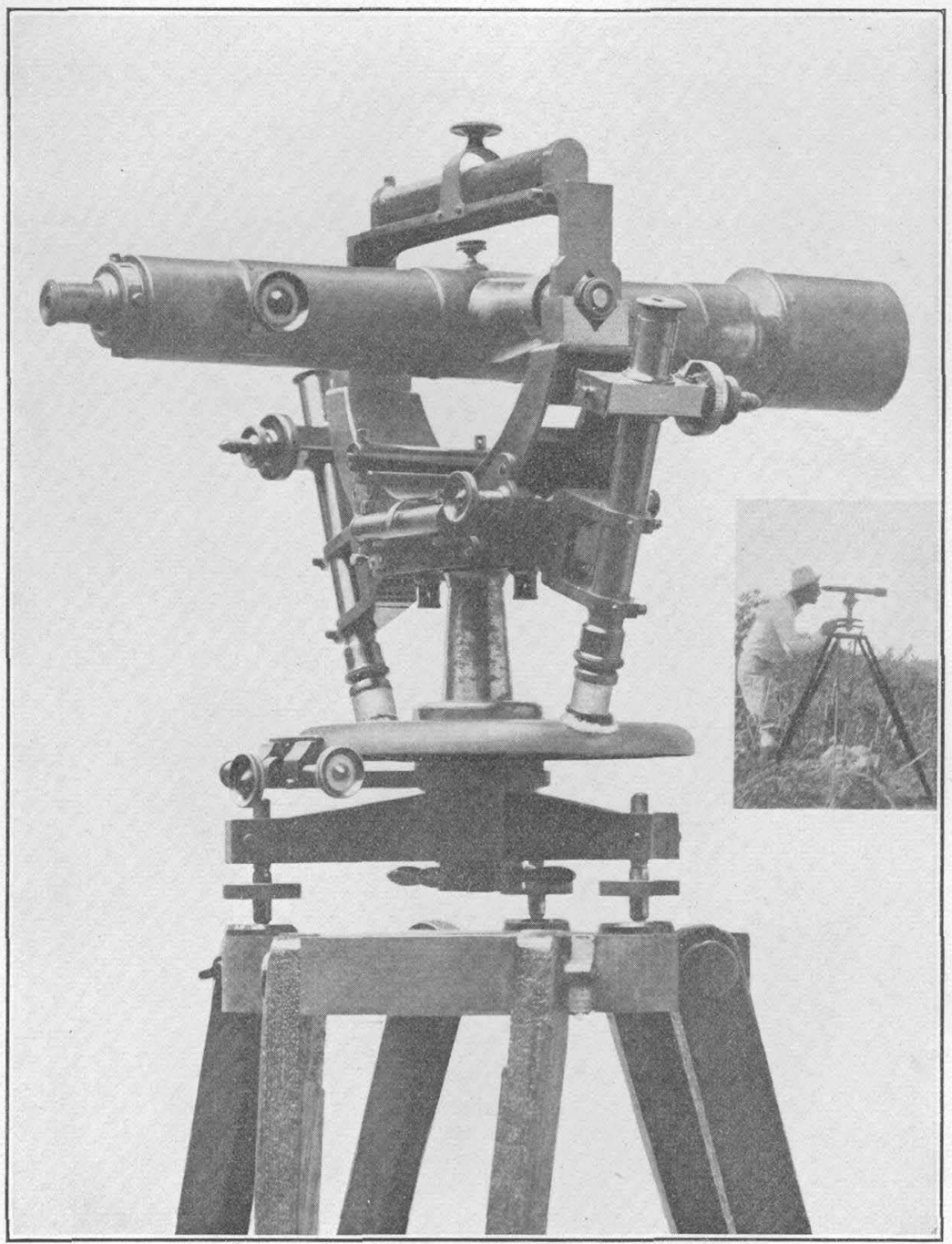

MICROMETER THEODOLITE 


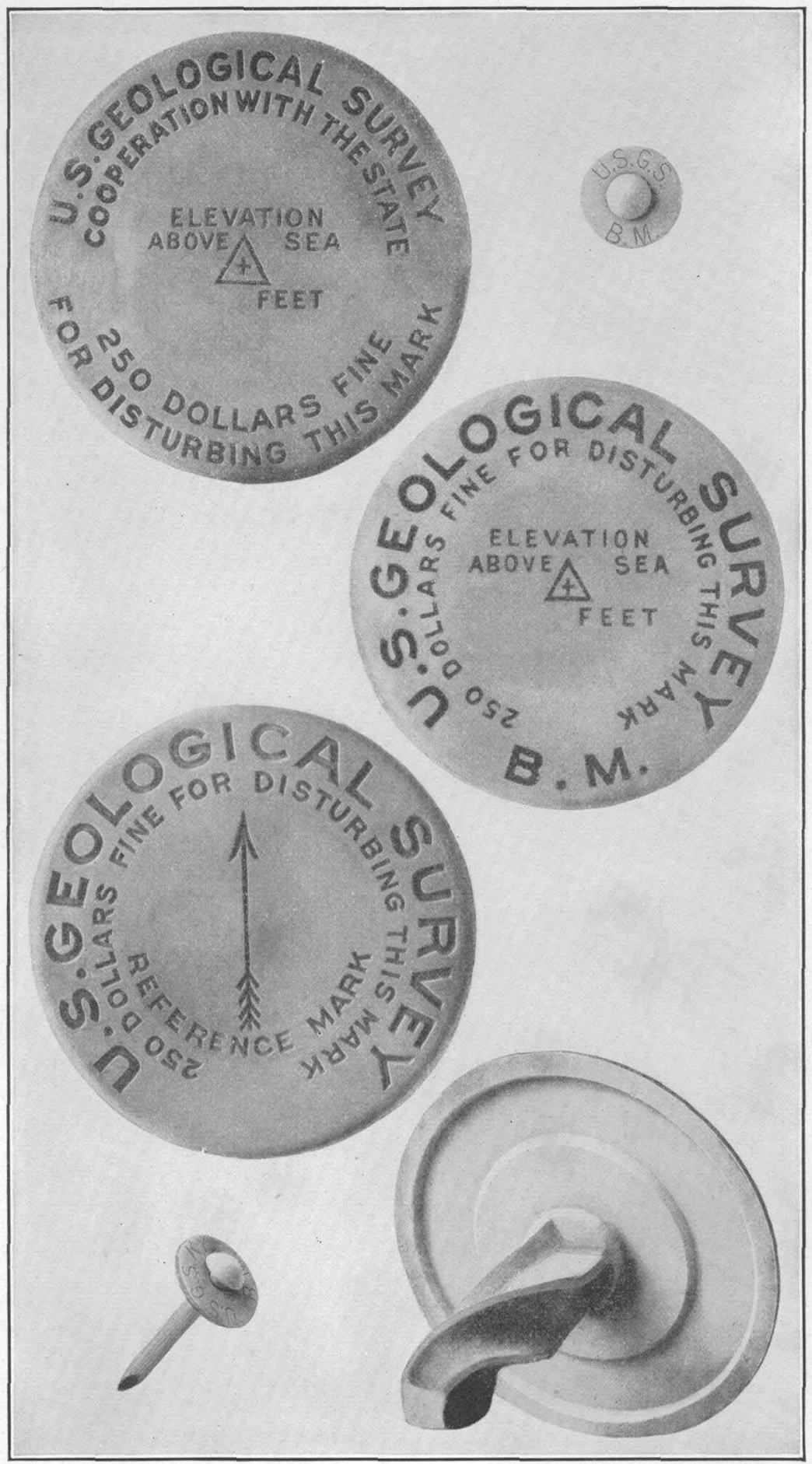

GEOLOGICAL SURVEY MARKS FOR TRIANGULATION, TRANSIT TRAVERSE, AND LEVELING 
Heliotroping.-The heliotrope outfit commonly used by the Survey is either the Steinheil or a plane mirror with a screw hinged to the back to give it universal motion and improvised diaphragms of tin or wood with round apertures. The plane mirror is generally preferred to a heliotrope of the more elaborate form.

A heliotrope is usually set up by mounting the mirror on a stake or board immediately over the center of the station and the diaphragm on another stake, 10 or 20 feet away, carefully aligned with the distant station. The operator must constantly watch the reflection from the mirror and keep it symmetrically over the aperture. If the sun is back of the observer a second mirror, a foot or two from the first, may be used to reflect the light into the first.

To the observer the flash should appear as a clearly defined point of light; if of appreciable size it will be necessary to bisect it, and an error is thus likely to be introduced. The apparent size of the flash depends more on the steadiness of the atmosphere than on the size of the aperture. An aperture greater than 1 inch will not be required in Geological Survey work.

\section{PERSONNEL AND OUTFIT OF PARTY}

In general each party consists of a chief of party, who acts as observer, and a recorder; also a cook and a teamster (or packer) when camping is necessary. Additional men are required for heliotroping, one for each heliotrope station, and local laborers may be employed to clear timbered summits or to erect large signals.

The following instruments and books are used in Geological Survey triangulation for map control:

One 8-inch theodolite, with leather carrying case and shoulder straps, or a transit.

Two pairs field glasses.

One prismatic compass.

One protractor (6-inch celluloid, full circle).

One boxwood scale, graduated to inches and tenths.

One 50-foot steel tape, meters on back.

Two electric hand lamps.

One 6-foot steel tape.

Heliotropes.

One plumb bob.

Triangulation tablets.

Cement, cans.

Signal notices, printed on cloth.

Climbing irons, for use in wooded regions.

Sun umbrella fFor use in regions where improvised sun and wind shelters

Wind screen $\}$ can not readily be built.

Triangulation field notes (9-912).

Computation of geodetic distances (9-901).

Computation of geodetic coordinates (9-902).

Computation book, blank (9-889).

Polaris positions for year.

Geographic tables and formulas (Bulletin 650).

Seven-place logarithmic tables.

A good watch must be provided by the chief of party. 
The following articles may be purchased in the field: Ax, hatchet, saw, nails, tacks, signal cloth, guy wire, stone drills (1 1/8-inch bit), drill hammer, posthole digger, wire cutter, and brace and bits.

For the standard triangulation of the Geological Survey an 8-inch theodolite reading by micrometer to 2 seconds of arc or by estimation to one-fifth of a second is used.

For the horizontal control of small areas inside of large triangles or inclosed by belts of triangles, a vernier theodolite or transit may with the approval of the division chief be substituted for the more accurate micrometer theodolite.

\section{CARE OF INSTRUMENTS}

Too much emphasis can not be laid upon the importance of care in the handling and transportation of instruments. Every employee intrusted with instruments in the field will be expected to keep them clean and in adjustment, to protect them from undue wear, and to return them to the custodian in fit order for use.

Minor repairs.-Each topographer should provide himself with a few simple tools and supplies, such as a small pair of pliers with side wire cutter, screw drivers of two sizes, small flat and round files, a spool of soft copper or brass wire, a few assorted brass nails and screws, a bottle of oil, a bottle of liquid shellac, spider web, and plaster of Paris, all of which may be used for minor repairs to instruments.

Field work should never be delayed by sending an instrument away for repair if the topographer can possibly repair it himself. Even crude repairs may often be made to serve until a new instrument can be procured.

Setting of bubbles.-For setting level bubbles a small supply of plaster of Paris should be kept on hand. For use the plaster should be mixed with water to the consistency of a thick paste. If plaster is lacking, strips of paper may be used, but these should never be jammed in very tight, as the pressure may distort the glass and thus vitiate the bubble reading by an appreciable amount. A reflecting surface of colored paper should be placed under the bubble in order to make the graduations more readable; a subdued green or blue tint is recommended.

Mounting of cross wires.-For mounting cross wires a small bottle containing shellac dissolved in alcohol, a pinch of beeswax, and a pair of dividers or a forked stick are needed. The best spider web is, of course, a freshly spun one from a small spider, for this will be both clean and elastic; but as spiders are not always available, it is well to keep on hand a spider cocoon. Such a cocoon will furnish webs enough to last for years, although with age the threads become stiff and brittle and therefore more liable to break from a jar to the 
instrument. Most webs taken from grass or bushes are rough, coarse, and dirty.

To draw the reticule from the instrument, unscrew and remove the eyepiece slide; then take out two opposite capstan-headed screws and loosen the other two. Using the latter two as handles, revolve the cross-wire ring $90^{\circ}$, insert a pointed stick through the end of the telescope tube into a screw hole in the ring, and, using it as a handle, remove the other capstan screws and draw out the ring. To replace it in the telescope, reverse this procedure. When in place the cross wires should be on the side of the ring toward the eyepiece.

Having pressed a bit of beeswax to each prong of the dividers or forked stick, let a small web fall from the end of one of the prongs, or pick with it from a cocoon a single thread, pressing the thread into the beeswax, stretch the thread moderately, and attach to the wax on the other prong. If an old web is used, it should first be dampened by dipping in water for a few seconds. In place of the dividers or forked stick, small sticks or lumps of wax may be attached to the web about 2 inches apart. Place the web across the reticule, using a magnifier to insure its coinciding exactly with the marked lines. Put a small drop of shellac on each end and leave until dry.

Cleaning instruments.-Instruments having working parts exposed to air and dust require cleaning from time to time. Such exposed parts as the threads of tangent screws are particularly liable to collect dust and grit and should be wiped frequently with an oily rag, then rubbed dry. Only the best quality of clock or watch oil should be used for this purpose.

Steel tapes should be cleaned and oiled after use. All moisture or grit must be wiped from them each time they are reeled, or they will deteriorate rapidly.

Neither the object glass nor the eyepiece of a telescope should ever be rubbed with rough cloth or with the fingers, as the glass may thus be permanently scratched. The lenses should never be removed from the cell that holds them nor separated from one another.

Packing and shipping.-In shipping instruments by freight or express transit and theodolite boxes must be filled in with paper or cloth, so that if any part of the instrument should jar loose during the journey it may not roll around in the box and damage other parts. Heavy articles, such as compasses, aneroids, or other small instruments, should never be placed in the instrument box. The micrometers of theodolites should be wrapped tightly with cloth, as they are easily jarred loose. The same precautions should be taken when these instrument are to be transported by pack train.

On no account should any instrument be shipped by express or freight in its own case only. A wooden box, large enough to permit a 
generous amount of excelsior, hay, or other padding around the instrument case, should be provided.

In mountains where pack trains are the sole means of conveyance the triangulator's outfit is most conveniently carried in a pair of canvas pack bags (alforjas), which must be properly balanced. The tripod, umbrella, and wind screens should be placed lengthwise on top, lashed to the saddle, and further balanced by properly disposing them on each side of the center. A canvas pack cover should be thrown over the whole and tucked in on all sides.

\section{ADJUSTMENT OF INSTRUMENTS}

\section{PRECAUTIONS}

The object glasses and eyepieces of all instruments must be properly focused. The cross wires projected against a distant object should appear immovable when the eye only is moved. Before the adjustments are commenced the instruments must be firmly set up and leveled. An instrument may appear to be out of adjustment simply because some part is loose. The object glass may be partly unscrewed or an adjusting screw may be only partly tightened; level bubbles or cross wires occasionally become loosened. Therefore, before commencing the adjustment of an instrument look out for such defects. When it is thought that an adjustment has been completed, always test it before using the instrument. All adjusting screws should be screwed tight enough to hold, yet not so tight as to injure the threads or put a severe strain on any other part. Especial care should be taken not to strain the cross-wire screws. Adjustments should be made in the order given under the following headings, for some adjustments depend on the accuracy of others previously made, and a change in any one may affect the others.

\section{MICROMETER THEODOLITE}

Striding level.-Place the level (pl. 3) in the proper position on the telescope axis. Level carefully with the horizontal plates clamped, and rock the level slowly back and forth till the foot pieces strike. If the bubble leaves the center, bring it back by means of the side adjusting screws near one end of the tube.

Reverse the level and bring the bubble halfway back to the center by raising or lowering one end of the tube with the screw at that end and the other half with the leveling screws. Repeat these operations till the adjustment is perfect.

Standards.-After the striding level is in adjustment with the lower horizontal circle clamped, level the instrument in two positions at $90^{\circ}$ from each other. Turn on the vertical axis $180^{\circ}$ from one position; if the bubble runs away from the center, bring it halfway 
back by loosening one of the large capstan-headed screws underneath the standards and tightening the other. Test the adjustment, and repeat it if necessary.

Plate levels.-Level instrument with the striding level only, then bring the bubbles of the plate levels to the center of their tubes by means of the end adjusting screws; or use the method described for adjusting the transit plate levels (p. 92).

Micrometers.-Each micrometer consists of three concentric tubes; the upper and lower ones slide in the central one. The lower tube, which holds the object lens when in proper position, is clamped to the middle one by means of the capstan-headed screw in the lower part of the I-shaped support. These two tubes may be moved together, or the lower one moved alone by loosening the proper screws. The upper tube contains the eyepiece lenses and is held in place by friction only.

Focus the eyepiece on the two parallel movable threads, and do not change it afterwards. With the eye in position for setting the micrometer, tighten one and loosen the other of the two screws that hold the I-shaped microscope support to the main frame of the theodolite until the figures and graduations on the plate appear to be in the center of the field.

Clamp the plate and by turning the micrometer screw set the two movable threads over a long graduation. Examine carefully to see whether they appear exactly parallel to it. If they are not parallel, loosen the two capstan-headed screws which clamp the micrometer tube, and twist the tube until the threads and mark appear parallel. Clamp the side screws lightly.

Set the movable cross wires on a division to the apparent left of the field of view as for a regular angle reading, read the micrometer head, and record the reading. Turn the graduated head about five turns, stopping when the threads are set on the next $10^{\prime}$ division to the right; read and record. Repeat this operation several times. If the mean of the left-hand readings is the same as the mean of the right-hand readings, or within one division of it, the adjustment may be accepted as satisfactory. An actual count of full revolutions should be made at least once; otherwise the adjustment might wrongly be thought perfect for $4 \frac{1}{2}$ or $5 \frac{1}{2}$ revolutions.

When the space covered by the two parallel micrometer threads, moved by exactly five revolutions of the micrometer screw, appears to be longer than one $10^{\prime}$ space on the graduated circle, to bring it into adjustment make the distance between the micrometer box and graduated plate longer by raising the middle part of the tube; but when the space is shorter than a $10^{\prime}$ space make that distance shorter also-that is, consider as connected or dependent the length of the thread space covered by an even five revolutions of the micrometer 
screw and the distance between the micrometer box and the graduated plate. When the former is longer than it should be, the latter should be made longer, if an adjustment is desired, and vice versa.

To make the adjustment, loosen the small capstan-headed screws which clamp the microscope tube; then, if the thread space is long, twist the middle part of the tube (including the micrometer box) back and forth and at the same time pull it upward, thus lengthening the distance to the graduated plate. When by estimation it has moved far enough, which can be roughly determined by the amount of blurring that results from the lower lens being thrown out of focus, clamp the upper capstan-headed screw. The lower part of the microscope tube holding the objective lens must now be twisted and gently pushed downward till the graduations again appear in focus. If the movable threads and graduations are not then parallel, the upper screw must be again loosened and the tube turned far enough to make them parallel, after which both screws' must be tightened. Test the adjustment by again measuring a $10^{\prime}$ space with the micrometer. If it is still out of adjustment, repeat these operations till it is satisfactory. When the adjustment has been completed a scratch may be made on the tube below each support and used as a guide in future adjustments.

The opposite micrometers may be placed $180^{\circ}$ apart by setting one at a reading of $0^{\circ} 0^{\prime} 0^{\prime \prime}$, with the comb scale exactly centered, and then centering the comb scale of the other micrometer over the $180^{\circ}$ mark by means of the capstan-headed screw at the left-hand end of its box. Bring the micrometer threads over the $180^{\circ}$ mark also; then, while holding the screw firmly in place, turn the graduated ring till it reads zero.

When setting the micrometer wires on a graduation, it is very important that they be moving toward the right when the turning of the screw is stopped. Should they be moved the least bit too far to the right, turn back not less than half a revolution of the screw and then bring them forward again. In general, when a setting is made by means of a screw working against a spring, the spring should always be undergoing compression when the motion stops.

Cross wires.-The vertical wire should be truly vertical; otherwise an exact adjustment of the cross wires is not essential.

After the striding level has been adjusted and the horizontal axis of the telescope carefully leveled, sight a distant point, raise and lower the telescope through an angle of $5^{\circ}$ or $10^{\circ}$, and note whether the cross wires follow the point. If not, loosen the cross-wire ring and twist slightly; repeat the adjustment if necessary.

Hold the striding level on the telescope parallel to the optical axis and, with the bubble in the center of the tube, set the intersection of the cross wires on a distant point and clamp both plates; lift the 
telescope out of its supports and turn $180^{\circ}$ around its optical axis; set it again on the selected point. If the striding level when placed on top of the telescope is horizontal and the vertical wire still cuts the point, the adjustment is complete. If not, shift the cross wires in either direction by means of the capstan-headed screws for one-half the apparent error. Repeat the test till the error is nearly all eliminated. Finally readjust the vertical wire, if necessary; or both wires may be put in place by revolving them in temporary wooden $Y_{j}$ supports.

\section{TRANSIT THEODOLITE}

The adjustments for striding level, standards, and plate ilevel are the same for the transit theodolite (pl. 2) as for the micrometer theodolite.

Collimation.-Level carefully, sight on a point about 500 feet aistant, raise or lower the telescope slightly, and note whether'the vertical wire remains on the point; if not, loosen the capstan-heaued screw and turn the cross-wire ring till the vertical wire will iremain on the point when the telescope is raised or lowered. Clamp the instrument, set the vertical wire so that it cuts the point selected; transit the telescope by revolving it $180^{\circ}$ on its horizontál axis, and select a second point 500 feet distant in the opposite direction from the first. Unclamp the upper plate, turn the transit $180^{\circ}$ on the vertical axis, set it on the point first selected, and again clamp the plate. Transit the telescope, and if the vertical cross wire exactly bisects the second point its adjustment is perfect; if it does not, bring it one-quarter of the way back to the second point by turning the two capstan-headed screws on the sides of the telescope.

Eyepiece tube.-The eyepiece may be put into, position over the cross wires by turning the screws that hold the eyepiece ring until the cross wires appear in the center of the field; an exact centering is not required.

Telescope level. - If there is a level attached to the telescope, it may be adjusted by the "peg method" after all the other adjustments are made, as follows. Level the transit and bring the bubble to the center of the tube under the telescope. Take a reading on a leveling rod or pole 300 or 400 feet distant, which is held on a stake set firmly in the ground. Revolve the transit $180^{\circ}$ on the vertical axis and after again bringing the bubble to the center set a second stake at the same distance as the first and at such an elevation that the rod or pole reading is the same as on the first stake. The tops of the two stakes will then be at the same elevation. "Move the transit 25 or 50 feet back of one stake and on a line with the other. Make the telescope as nearly horizontal as possible by means of the attached level, clamp it, and then take a reading on the rod held on the near stake and another reading on the distant stake. If the two readings agree, $58515^{\circ}-28-5$ 
the telescope is horizontal; if they do not agree, turn the tangent screw so as to bring the cross wire while set on the distant rod nearly to an agreement; repeat the operation until an agreement is reached. The teleszope is then level, and the adjusting nuts at the end of the level tube should be turned until the bubble is brought to the center.

Vertical circle or arc.- - The screws holding the vernier for the vertical arc should now be loosened and the vernier moved until the reading is $0^{\circ}$ while the telescope is still level. If there is no level under the telesiope, the level attached to the vertical-circle vernier arm may be adjusted after the striding level and standard are adjusted, by revolving the instrument on its vertical axis and turning the slowmotion tangent screw (attached to the vernier arm) until the bubble remains in the center during an entire revolution. The index error of the vertical circle may then be found, and the vernier moved till the reading is $0^{\circ}$.

\section{OBSERVING AND RECORDING}

Time of observing.-As a rule, the best time for observing is during the three hours before sunset; the atmosphere is then steadiest and shows no "boiling." The early morning hours are occasionally good but are likely to be less satisfactory. Cloudy or overcast days may be fayorable. As a last resort, observations at night may sometimes be necessary, but these require special night signals and assistants to operate them and because of the additional cost involved are seldom warranted.

Preparation for observing.-Wherever practicable the theodolite niust be set over the station mark for reading angles, to obviate reduction to center. In setting up the tripod the head-bolt thumbscrews must be left loose until the legs are firmly placed and then tightened.

The instrument must be sheltered from both wind and sun. If the region affords no material readily available for constructing wind screens and isun shelters, a folding wind screen and a sun umbrella must be carried as a part of the regular outfit.

Before observations are begun at a station all adjustments of the theodolite must be tested and such as are found in error must be corrected, special attention being paid to the micrometers to eliminate errors of run. The stations to be sighted must next be carefully identified by means of the directions shown on the plat or by means of angles previously taken with a prismatic compass. If any of the distant stations can not be seen with the unaided eye, some object in line with each which can be found quickly must be selected, or, if necessary, the direction to each may be marked by some object near by, so that no time need be lost in making the pointings when the angles are being res-1.

Method of observing.-With micrometer theodolites either single angles may be measured or circle readingis (directions) may be made. In using the latter method select for the initial point some station 
that is especially distinct and easily sighted and use it as the initial point for all sets of readings. The telescope being set on the initial point, read both micrometers, then sight the other stations in succession in the order of their azimuths (clockwise rotations), closing on the initial point. Then reverse telescope, set on initial point, and sight the stations in reverse order. This completes one set of readings with telescope direct and reverse. Now shift the circle about $45^{\circ}$ (examine the plate bubbles after this shift and relevel if necessary) and begin another set. When pressed for time, shift the circle when telescope is reversed. No angle should be considered well determined that has not been measured on at least four different parts of the circle or eight times in all, four with telescope direct and four with telescope reversed. When the telescope is reversed, each end of its axis will rest in the same $Y$ as before. Reversals and releveling are of especial importance where there is an appreciable difference in the elevations of the points sighted.

If the observations are made in the afternoon, take all secondary pointings before commencing the observations to stations, and make at least two sets of such pointings; the remaining time for observing can then be devoted to the accurate measurement of the important angles while conditions are the most favorable.

The graduated circle should never be placed so that when pointing at any particular station the micrometers will be set to even degrees, except, as before noted, while data are being obtained for "reduction to center."

Field record.-The field record is to be kept in book 9-912. It must be written in a plain neat hand with a No. 4 pencil or in ink, and no part of it must on any account ever be erased. A single line should be drawn through erroneous records, the corrected figures being written above. If deemed necessary, an explanation should be written in the column for remarks. The memory should not be trusted for data of any kind; the record must be faithfully kept in all particulars and must be made so complete that it can be understood by another person at any time.

On the flyleaf of each field notebook is a blank in which all information necessary to identify the book may be recorded. This blank should be filled so far as practicable on or before the first date of entry of field notes, and it must be completely filled before the book is forwarded to the Washington office. Any failure to fill in completely the blank on the flyleaf of a field notebook should be reported by the computer to the division engineer. One of the blank flyleaves must contain an index of the contents. The date, name of station, time of observing, and names of observer and recorder should be systematically entered at the head of each page.

The position of the instrument with respect to the center of the station must be clearly defined, and if it is set up off the center a full statement must be given of the distance and the angles measured. 
On the page immediately preceding the record of angles should be written a minute and complete description of the station occupied, the station's marks, character of signal, nearest camping or other stopping places, roads, and trails, also a statement regarding the ownership of the land and such other information as will be helpful to the topographer. The description must be written before the recorder leaves the station and should be accompanied by a rough diagram showing directions to other stations and plan indicating location of instrument or signal if it was not centered on the station.

The following is a suitable station description:

ELK, LEWIS COUNTY, KY.

About 4 miles north of Petersville and 2 miles south of Glen Springs, on a cleared round knob at the head of Elk Lick and Black Lick, branches of Kinniconick Creek. George Washburn lives at base of hill on north side, and his place can be reached by road up Elk Lick. An excellent view in every direction.

Signal: Chestnut oak about 14 inches in diameter; distance 8.3 feet, true azimuth from station mark, $58^{\circ} 11^{\prime}$.

Station mark: Stone post with tablet in top, set 30 inches in ground and resting on bedrock.

Underground mark: A + cut in rock.

A plat, drawn to scale, should always be prepared and forwarded to the office with the field notes.

Reading and recording of angles.-When the micrometer wires are set for a reading with the Geological Survey theodolites it is very important that the last movement of the wires be toward the right. The readings on the graduated head are then decreasing, and the spring attached to the slide that holds the wires is being compressed. If the cross wires are moved the least bit too far to the right they must not be turned backward merely to the setting but must be turned backward at least a half turn of the screw and then brought forward slowly to correct setting. When the setting is properly made a division on the graduated plate will appear exactly midway between the two movable cross wires, and an equal amount of white space will show on each side of it. A part at least of the micrometer adjustment in errors can be eliminated by making the settings with less than five turns of the screw; this can always be done if the right-hand part of the comb scale is sometimes used for comb-scale and micrometerhead readings, the 10-minute space being taken from the left.

For all precision instruments in which a tangent screw and spring are used together, the setting should be made while the spring is being compressed; otherwise the "slack" of the screw may cause an error.

The recorder should not only take down the readings called off by the observer but should without delay compute the angles between successive stations and also the mean readings. The following form is to be used for recording angles by the method of directions: 


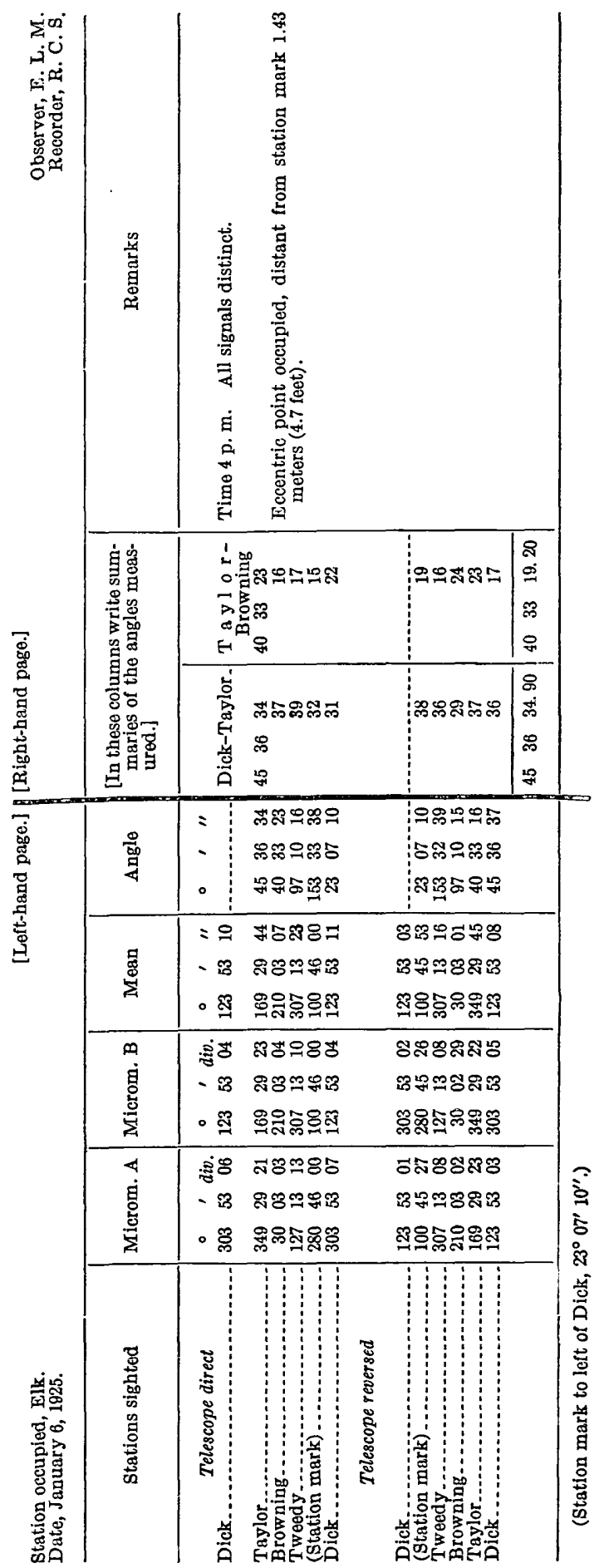


In this example five sets of circle readings direct and five reversed were taken. The angles between stations were found by subtracting the mean reading at one station from that for the next following They are grouped in these columns merely for convenience; they may fill several pages. The next group on this or a following page would represent the angle Browning to Tweedy, and so on.

Only two readings on the station mark need be taken for reduction to center.

Opposite each angle record any necessary information as to visibility of signals or atmospheric conditions.

Field computations.-Angles at each station should be reduced to center in the field in order to test the triangle closures, which for Geological Survey work should seldom exceed 10 seconds or average more than 5 seconds.

Arbitrary adjustments and preliminary computations of positions should also be made in the field. Book 9-889 should be used for summary of angles and for miscellaneous computations. Computations for distances should be entered in book 9-901 and for coordinates in book 9-902. For field computations of coordinates where the lines are short, five or six place logarithms will give sufficient accuracy, and the computations may be shortened by omitting some of the minor corrections, carrying results to tenths of seconds of latitude and longitude only.

As soon as the preliminary computations are made the record books should be sent to the Survey office by registered mail. The computation books should also be sent by registered mail but on another day.

Triangulation plot.-A careful plot of the work should be kept on the scale of 8 miles to an inch, and each month a reduced copy, on which angles measured are indicated by the usual sign, should be sent in on the monthly report blank. If this plot is carefully made it can be transferred directly to the office State progress map.

In order to use the plot for finding the direction to distant stations place the protractor on it with $0^{\circ}$ in line with a station that can be seen clearly; then read in turn the angle to each other station, thus obtaining an observing list.

Azimuths.-Two true azimuths should generally be available for each square degree covered by the triangulation. These may be previously computed azimuths from independent sources or may be obtained by direct observations on Polaris.

Azimuth observations.-An azimuth mark should be placed at least half a mile from the station. It should consist of a vertical slit onefourth to one-half inch wide and 6 inches long, cut in a small box containing a candle or lantern. To illuminate the cross wires of the instrument and to read the angles, an electric hand lamp is to be preferred. 
The observations should consist of not less than five direct and five reversed measurements between the star and mark. As the star is at a much higher angle of elevation than the mark, it is important that the horizontal axis of the theodolite be adjusted with care and leveled. The ends of the striding-level bubble must be read at each setting on the star and a level correction computed if there is an appreciable difference between them, as shown in the example below.

Observations on Polaris should be made immediately before and after elongation, as any error in the time of observation has then the least effect on the resulting azimuth. The time of setting the cross wires on the star must be recorded to the nearest second. The watch error must be known, and to this end the observer should compare his watch frequently with telegraphic time, which is sent over Western Union lines once a day, usually at noon, Washington standard time. The time meridian for which the watch is set must always be recorded; if "daylight saving" time is used, that fact must also be stated.

\section{Example of record of azimuth observations}

Station: Elk, Ky. 8-inch theodolite No. 434. One division of micrometer $=2^{\prime \prime}$. One division of level $2^{\prime \prime}$ of arc. January 6,1925 . Watch $0^{\mathrm{m}} 23^{\mathrm{eec}}$ slow, $75 \mathrm{th}$ meridian standard time

Telescope direct

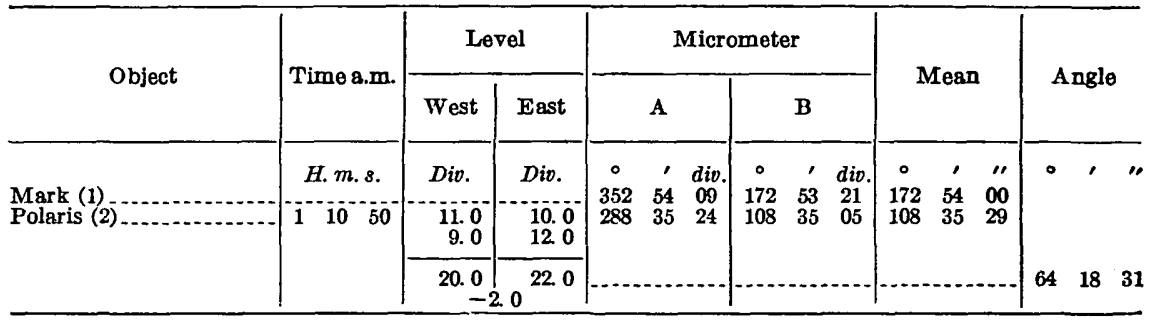

Telescope reversed

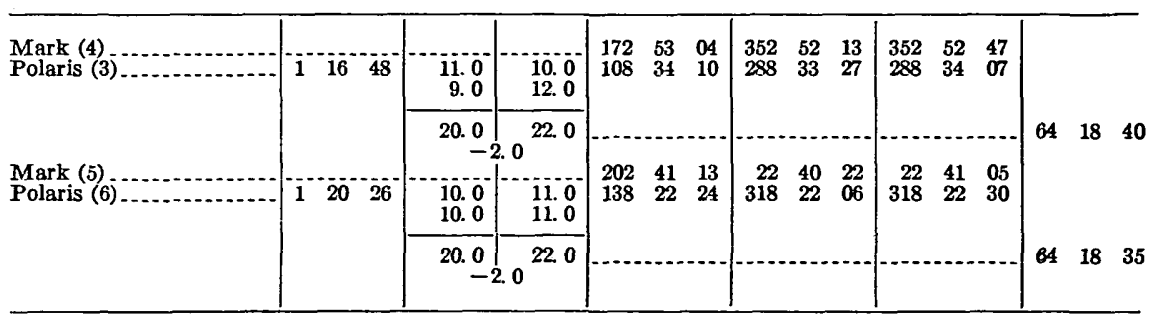

Telescope direct

\begin{tabular}{|c|c|c|c|c|c|c|c|c|c|}
\hline \multirow[t]{2}{*}{ Polaris ............... } & \multirow[t]{2}{*}{$126 \quad 52$} & $\begin{array}{l}\text { 10. } 0 \\
11.0\end{array}$ & $\begin{array}{l}11.0 \\
10.0\end{array}$ & \multirow[t]{2}{*}{$\begin{array}{rrr}22 & 41 & 07 \\
318 & 22 & 20\end{array}$} & \multirow[t]{2}{*}{$\begin{array}{lll}202 & 40 & 17 \\
138 & 22 & 13\end{array}$} & \multirow[t]{2}{*}{$\begin{array}{lll}202 & 40 & 54 \\
138 & 22 & 33\end{array}$} & \multirow{2}{*}{\multicolumn{2}{|c|}{641}} & \multirow[b]{2}{*}{21} \\
\hline & & $\begin{array}{l}21.0 \\
0 .\end{array}$ & 21.0 & & & & & & \\
\hline
\end{tabular}

NoTE.-Four other sets should be taken. 


\section{TRIANGULATION COMPUTATIONS}

Preliminary computations of distances from unadjusted angles should be made in the field, as required by the rule on page 64 .

The steps in the final adjustment and computation are set forth below.

Operations are completed in books 9-912, 9-889, 9-901, and 9-902. The results are tabulated on printed blanks 8 by $101 / 2$ inches in size, one blank for each station.

\section{CLOSING THE HORIZON}

In careful work closing errors will always be small and may be distributed among the angles in proportion to their number. If any of the angles measured should equal the sums of smaller angles, proper adjustments must be made before the horizon is closed.

\section{TABULATION OF ANGLES}

For convenience of reference a rough plot should be made for each station on part of a page in book 9-889, showing the relative size and position of the angles with names of stations sighted, and on the same or the foilowing page should be given a summary of all the angles at the station, in order of azimuth, with the angles and distances to signals for eccentric stations.

\section{REDUCTION TO CENTER}

For eccentric stations the data for reduction to center should be indicated on the plat, and figures should be given for them in the summary. An illustration of the method of producing these data is given below. (See also fig. 2, p. 78.) Two sets of angles were read at Elk station (where an eccentric point was occupied), with one of the micrometers set very nearly on $100^{\circ} 45^{\prime}$ when the telescope was pointing directly toward the center of the signal. The angle to each point in turn is given below. By measuring the angle with one micrometer reading $0^{\circ} 00^{\prime}$ the computer would have been saved considerable trouble and the possibility of error would have been lessened. The measured distance between the center of the instrument and the center of the station was 4.7 feet ( 1.43 meters).

The formula for computing the swing in seconds for any line is:

$\frac{\text { Distance to signal }}{\text { Sine } 1^{\prime \prime}} \times \frac{\text { Sine of angle between signal and far station }}{\text { Distance to far station }}$

The distance to signal will be a constant for each set up, hence its logarithm may be combined with the sine of $1^{\prime \prime}$ and this constant used throughout the computation. The distances to the distant stations in logarithms of meters are derived from a preliminary computation.

$$
\begin{array}{ll}
\log 1.43 & =0.15534 \\
\log \sin 1^{\prime \prime} & =4.68557 \\
\text { constant } & =5.46977
\end{array}
$$


ELK STATION

\begin{tabular}{|c|c|c|c|c|}
\hline Station. & Dick & Taylor & Browning & Tweedy \\
\hline Angle.............. & $23^{\circ} 07^{\prime} 10^{\prime}$ & $68^{\circ} 43^{\prime} 40^{\prime \prime}$ & $109^{\circ} 16^{\prime} 54^{\prime \prime}$ & $206^{\circ} 27^{\prime} 10^{\prime}$ \\
\hline $\begin{array}{l}\text { Log constant. } \\
\text { Log sine angle. } \\
\text { A. C. } \log \text { distance. }\end{array}$ & $\begin{array}{l}5.46977 \\
9.59400 \\
5.70154 \\
\end{array}$ & $\begin{array}{l}5.46977 \\
9.96935 \\
5.59196\end{array}$ & $\begin{array}{l}\text { 5. } 46977 \\
\text { 9. } 97493 \\
\text { 5. } 74781 \\
\end{array}$ & $\begin{array}{l}5.46977 \\
9.64881 \\
5.63275 \\
\end{array}$ \\
\hline $\begin{array}{l}\text { Log correction } \\
\text { Correction in seconds }\end{array}$ & $\begin{array}{r}0.76531 \\
+5.83\end{array}$ & $\begin{array}{l}1.03108 \\
+10.74\end{array}$ & $\begin{array}{r}1.19251 \\
+15.58\end{array}$ & $\begin{array}{r}0.75133 \\
-5.64\end{array}$ \\
\hline
\end{tabular}

The sign for any correction is the same as that for the sine of the angle, therefore for an angle over $180^{\circ}$ it will be negative.

The correction for any angle will be the difference between the corrections for the two lines bounding it, the lines always being taken in order of azimuth.

Thus, for Dick-Elk-Taylor it will be

$$
\begin{aligned}
& +10.74 \\
& -5.83 \\
& +4.91^{\prime \prime} \\
& \text { For Browning-Elk-Tweedy it will be } \\
& -5.64 \\
& -15.58 \\
& -21.22
\end{aligned}
$$

The general rule is, change the sign of first correction (in order of azimuth) and add algebraically to the second correction. The sum will be the correction to the angle. The angles listed on page 72 have all been corrected.

The foregoing formula may be used also when it is desired to compute the swing for a line, which is to be applied at a distant station to change the pointing to the marked point-that is, the station center-from that taken to the signal. Whether the computed swing is to be added to or subtracted from a given angle may easily be found by an inspection of the diagram.

\section{COMPUTATION OF AZIMUTH OBSERVATIONS}

The daily change in Polaris is so slight that for the following computation no account need be taken of a fraction of a day in computing its position:

Elk sta., Ky. Lat. $37^{\circ} 28^{\prime} 47^{\prime \prime}$, long. $82^{\circ} 00^{\prime} 16^{\prime \prime}$.

January 6,1925 , at $1^{\text {b }} 10^{\mathrm{m}} 50^{\mathrm{s}}$ a. m. watch time.

Watch 23 seconds slow, 75th meridian (standard) time.

Long. $82^{\circ} 00^{\prime} 16^{\prime \prime}=75^{\circ}+7^{\circ} 00^{\prime} 16^{\prime \prime},=5^{\mathrm{b}} 28^{\mathrm{m}} 01^{\text {" }}$ west of Greenwich, $=28^{\mathrm{m}} 01^{\mathrm{s}}$ west of $75^{\circ}$.

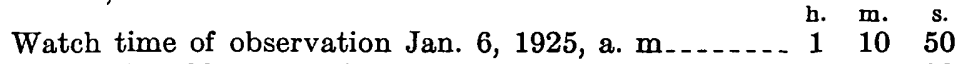

Watch slow $23^{\mathrm{s}}$; correction ......

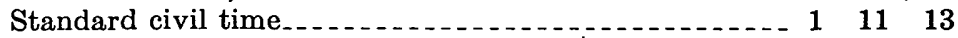

Correction to local meridian.............

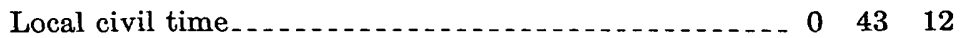

Longitude in time..........

Time after $0^{\mathrm{h}}$ Greenwich....................... 6 6 $11 \quad 13$

$6 \quad 11.22$

6. 187 hours

1 Commencing Jan. 1, 1925, the civil and astronomic days begin at midnight. Astronomic hours are counted from 0 h at midnight to $24 \mathrm{~h}$ the following night. Prior to 1925 the astronomic day commenced at noon 12 hours later than the civil day. 


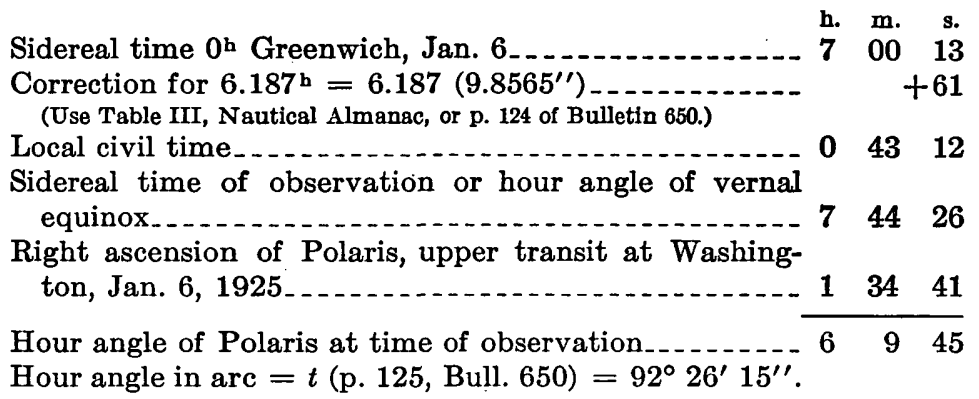

The hour angle of Polaris can be computed with sufficient accuracy from the tables in the General Land Office ephemeris as follows:

Greenwich mean time of nearest upper culmination of Polaris, Jan. 5, 1925, p. m. (General Land Office h. m. s. ephemeris) _. . . . _ .

Reduction to longitude $82^{\circ} 00^{\prime} 16^{\prime \prime}$ (Bull. 650, p. 126)

Local mean time of upper culmination......... . $6 \quad 34 \quad 30$

Local mean time of observation, Jan. 6, 1925, a. m. $\left(1^{\mathrm{h}} 11^{\mathrm{m}} 13^{\mathrm{s}}-28^{\mathrm{m}} 1^{\mathrm{s}}\right) \ldots \ldots$

Mean time hour angle (or time interval from upper culmination to observation) . .

Reduction to sidereal hour angle (Bull. 650, p. 126) - - $+1 \quad 1$

Sidereal hour angle............. $6 \quad 943$

The difference of 2 seconds between this and the figures obtained above for the hour angle is the result of the dropping of decimals in the General Land Office tables.

The following are the formulas for azimuth and level correction:

$$
\tan A=-\frac{\alpha \sin t}{1-b \cos t} \quad \alpha=\sec \phi \cot \delta \quad b=\tan \phi \cot \delta
$$

Level correction $=-\frac{d}{4}\left[\left(w+w^{\prime}\right)-\left(e+e^{\prime}\right)\right] \tan h$.

in which, for the example above given,

$\phi=$ latitude of station $\left(37^{\circ} 28^{\prime} 47^{\prime \prime}\right)$.

$A=$ azimuth of Polaris at time of observation.

$\delta=$ declination of Polaris at time of observation $\left(88^{\circ} 54^{\prime} 24^{\prime \prime}\right)$.

$t=$ hour angle of Polaris at time of observation $\left(92^{\circ} 26^{\prime} 15^{\prime \prime}\right)$ (the cosine is negative, sine plus in this example), value of one division of level $\left(2.0^{\prime \prime}\right)$.

$w, w^{\prime}=$ readings of west end of level bubble, direct and reversed.

$e, e^{\prime}=$ readings of east end of level bubble, direct and reversed.

$h=$ angular elevation of star (at elongation this is equal to the latitude, nearly).

The level correction is used as a correction to azimuth $A$ only. 
Each azimuth computation should be made in a single column and for convenience the columns should be placed side by side in tabular form.

The following is the computation of this observation:

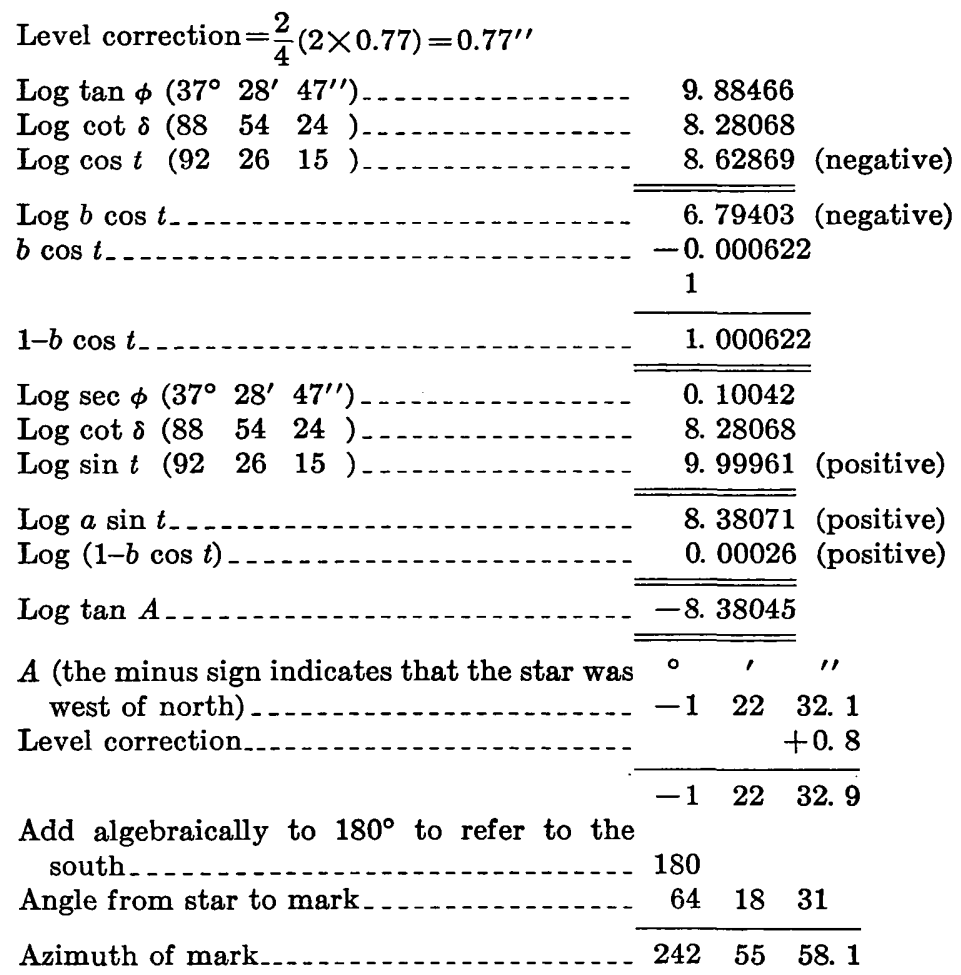

\section{TABULATION OF TRIANGLES}

By an inspection of the field plat of the triangulation determine what groups of triangles are so interrelated that a change in one will affect the others and what groups of triangles should be adjusted as a unit. For the triangulation by the Geological Survey, which is not executed for geodetic purposes, it is not advisable to include more than fifteen or twenty triangles in such a group, because the labor of solving equations for the adjustment of any group increases rapidly with its size. Four overlapping triangles form one of the simplest groups that may be adjusted by the usual least-square methods.

Assume the group shown in Figure 1 for adjustment. Tabulate the angles for each triangle, as shown at (a), (b), (c), and (d) (p. 72). Any angle in any of these triangles may be considered as the difference between the azimuths (directions) of its two sides. For 
example, angle Dick-Elk-Taylor, or 4.3.1, as designated for convenience by the figures assigned to each angle vertex, would be the azimuth or direction of the line 4.3 subtracted from the azimuth or direction of the line 1-3. Azimuths are always measured in a clockwise direction. Therefore this angle may be indicated as $-4.3+1.3$

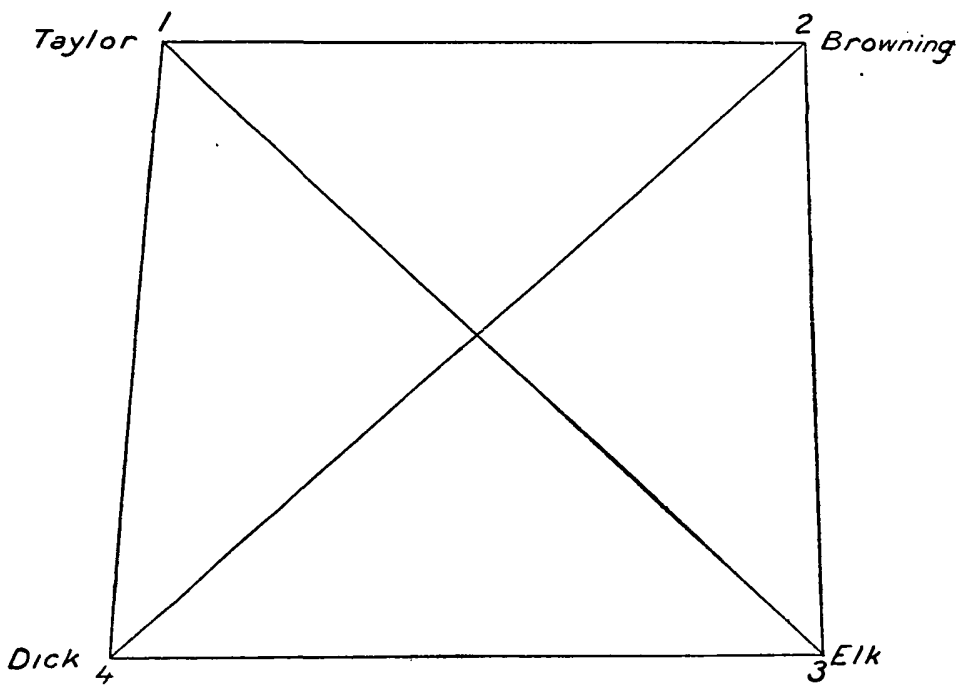

Fig URE 1.-Quadrilateral for adjustment by least-square method

or $-4 / 3+1 / 3$. In the latter form the denominator is always the figure at the vertex of the angle, and with the vertex pointing toward the observer the left-hand direction is always given the minus sign. (Directions will hereafter be referred to as sides.)

\section{COMPUTATION OF-SPHERICAL EXCESS}

For any triangle on the earth's surface the sum of the three angles, if correctly measured, will exceed $180^{\circ}$ by an amount varying with the area. For use in computing distances the observed angles must be reduced to their plane values by deducting one-third the spherical excess from each. The spherical excess for any triangle between la $a^{\prime}$ itude $25^{\circ}$ and $45^{\circ}$ is approximately 1 second for each 75.5 square miles of area, or exactly equals in seconds $a b m$ sin $C$, in which $a, b$, and $\mathrm{C}$ are, respectively, the lengths of the two sides in meters and the included angle of any triangle, and $m$ is a constant depending on the latitude. ${ }^{2}$

In computing spherical excesses for any figure (as fig. 1, for example) arrange the work systematically, the logarithms of each of two

${ }^{2}$ Logarithms of $m$ are given in Geographic tables and formulas, U. S. Geol. Survey Bull. 650, p. $294,1918$. Between latitudes $30^{\circ}$ and $50^{\circ} \log m$ may be found with sufficient accuracy for preliminary computations from the formula $1.4040+\left(45^{\circ}-\phi^{\circ}\right.$, used as a unit in the fourth decimal place). For example: Lat. $37^{\circ}$, 45- $\phi=8, m=1.4048$ (tabular value $=1.40482$ ); lat. $49^{\circ}, 45-\phi=-4, m=1.4036$ (tabular value=1.40359). 
sides in meters from a preliminary computation, the logarithm of the sine of their included angle, and the logarithm of $m$ for the mean latitude for each triangle; place in a column. Give the figures for the triangle at the head of the column, as 4.3.1, using the angle 4.3.1 and the sides 4-3 and 1-3 in the computation.

Computation for spherical excess

\begin{tabular}{|c|c|c|}
\hline Triangle & 4.3 .1 & 1.3 .2 \\
\hline $\begin{array}{l}\text { Log side } a \\
\text { Log side } b=0 \\
\text { Log sin } C=0\end{array}$ & $\begin{array}{l}4.29846 \\
4.40804 \\
9.85406 \\
1.40475\end{array}$ & $\begin{array}{l}\text { 4. } 40804 \\
\text { 4. } 25219 \\
9.81304 \\
1.40475\end{array}$ \\
\hline $\begin{array}{l}\text { Log spherical excess } \\
\text { Spherical excess in seconds }\end{array}$ & $\begin{array}{r}9.96531 \\
0.92\end{array}$ & $\begin{array}{r}9.87802 \\
0.76\end{array}$ \\
\hline
\end{tabular}

Mean latitude, $37^{\circ} 35^{\prime}$.

In the same manner compute the spherical excess for each of the remaining triangles. Many such computations can be conveniently made in the book (9-901) used for preliminary distances, in the left-hand column adjacent to each triangle.

As the spherical excess for a given area is constant, the sum of the spherical excesses for the triangles 1.3.2 and 4.3.1 must equal the spherical excesses for the other two. This check should always be applied to the results.

\section{LEAST-SQUARE ADJUSTMENT}

By the least-square adjustment of a triangulation net, the most probable values are found from the more or less discordant measurements. These will not necessarily be the true values but they will be such as to produce consistent results. A line or position computed from them will be the same even if computed from different sets of triangles.

After deducting the spherical excesses from the sums of angles for each triangle $(a),(b),(c),(d)$ (see below), the differences between the remainders and $180^{\circ}$ will be the errors, plus for remainders over $180^{\circ}$ and minus for those less than $180^{\circ}$.

The algebraic sum of the closing errors of two of the triangles (of any quadrilateral) should equal the algebraic sum of the closing errors of the other two which cover the same area:

$$
\begin{array}{ll}
-3.45 & +2.74 \\
+4.70 & -1.49 \\
\hline+1.25 & +1.25
\end{array}
$$

This check should always be applied. 
The rules for determining the number of angle equations and the number of sine or side equations required for the proper adjustment of any figure are these:

$$
\begin{aligned}
& L-S+1=\text { angle equations. } \\
& L-2 S+3=\text { side equations. }
\end{aligned}
$$

where $L$ equals the number of lines in the figure observed in both directions and $S$ the number of stations. A solution of these equations for a quadrilateral shows that three angle equations and one side equation are required. In selecting the equations for a large group of triangles, it is well to consider each part of the figure in detail, commencing with three stations, adding stations with the lines to them one at a time, and at each step computing the angle and side equations required.

The side equation in a quadrilateral fixes the condition that three lines shall meet in one point.

In the present example it is immaterial which three of the four triangles are used for the adjustment.

\begin{tabular}{|c|c|c|c|c|c|c|}
\hline Stations & Side & Observed angle & $\begin{array}{c}\text { Correc- } \\
\text { tion }\end{array}$ & $\begin{array}{r}\text { Cor } \\
\text { spher }\end{array}$ & r & ted \\
\hline \multirow[t]{2}{*}{ (a) $\left\{\begin{array}{l}\text { Elk } \\
\text { Taylor } \\
\text { Browning- }\end{array}\right.$} & \multirow[t]{2}{*}{$\begin{array}{l}-1 / 3+2 / 3 \\
-2 / 1+3 / 1 \\
-3 / 2+1 / 2\end{array}$} & $\begin{array}{ccc}\circ & \prime & \prime \prime \\
40 & 33 & 19.17 \\
44 & 03 & 30.52 \\
95 & 23 & 07.62\end{array}$ & \multirow[t]{3}{*}{$\begin{array}{l}\prime \prime \\
+2.13 \\
+0.61 \\
+0.71\end{array}$} & $\begin{array}{l}\circ \\
40 \\
44 \\
95\end{array}$ & $\begin{array}{l}1 \\
33 \\
03 \\
23\end{array}$ & $\begin{array}{c}\prime \prime \\
21.30 \\
31.13 \\
08.33\end{array}$ \\
\hline & & $\begin{array}{rrr}179 & 59 & 57.31 \\
\text { Spherical excess } & 0.76\end{array}$ & & 180 & 00 & $\begin{array}{l}00.76 \\
-0.76\end{array}$ \\
\hline \multirow{4}{*}{ (b) $\left\{\begin{array}{l}\text { Dick } \\
\text { Taylor } \\
\text { Browning- }\end{array}\right.$} & \multirow{4}{*}{$\begin{array}{l}-1 / 4+2 / 4 \\
-2 / 1+4 / 1 \\
-4 / 2+1 / 2\end{array}$} & Error_........ -3.45 & & & & \\
\hline & & $\begin{array}{lll}40 & 09 & 14.16 \\
94 & 38 & 08.09 \\
45 & 12 & 37.04 \\
\end{array}$ & \multirow[t]{3}{*}{$\begin{array}{l}-0.90 \\
+0.21 \\
+2.18\end{array}$} & $\begin{array}{l}40 \\
94 \\
45\end{array}$ & $\begin{array}{l}09 \\
38 \\
12\end{array}$ & $\begin{array}{l}13.26 \\
08.30 \\
39.22\end{array}$ \\
\hline & & 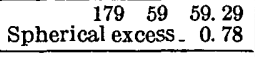 & & 180 & 00 & $\begin{array}{r}00.78 \\
-0.78\end{array}$ \\
\hline & & Error $_{\ldots} \ldots \ldots \ldots-1.49$ & & & & \\
\hline \multirow[t]{3}{*}{ (c) $\left\{\begin{array}{l}\text { Elk } \\
\text { Dick } \\
\text { Taylor }\end{array}\right.$} & \multirow[t]{3}{*}{$\begin{array}{l}-4 / 3+1 / 3 \\
-1 / 4+3 / 4 \\
-3 / 1+4 / 1\end{array}$} & $\begin{array}{lll}45 & 36 & 34.90 \\
83 & 48 & 53.15 \\
50 & 34 & 37.57 \\
\end{array}$ & \multirow[t]{3}{*}{$\begin{array}{l}-2.97 \\
-1.33 \\
-0.40\end{array}$} & $\begin{array}{l}45 \\
83 \\
50\end{array}$ & $\begin{array}{l}36 \\
48 \\
34\end{array}$ & $\begin{array}{l}31.93 \\
51.82 \\
37.17\end{array}$ \\
\hline & & $\begin{array}{rrr}180 & 00 & 05.62 \\
\text { Spherical excess. } & 0.92 \\
\end{array}$ & & 180 & 00 & $\begin{array}{r}00.92 \\
-0.92\end{array}$ \\
\hline & & Error_.......... +4.70 & & & & \\
\hline \multirow[t]{3}{*}{ (d) $\left\{\begin{array}{l}\text { Elk } \\
\text { Dick- } \\
\text { Browning-- }\end{array}\right.$} & \multirow[t]{3}{*}{$\begin{array}{l}-4 / 3+2 / 3 \\
-2 / 4+3 / 4 \\
-3 / 2+4 / 2\end{array}$} & $\begin{array}{lll}86 & 09 & 54.07 \\
43 & 39 & 38.99 \\
50 & 10 & 30.58\end{array}$ & \multirow[t]{3}{*}{$\begin{array}{l}-0.84 \\
-0.43 \\
-1.47\end{array}$} & $\begin{array}{l}86 \\
43 \\
50\end{array}$ & $\begin{array}{l}09 \\
39 \\
10\end{array}$ & $\begin{array}{l}53.23 \\
38.56 \\
29.11\end{array}$ \\
\hline & & $\begin{array}{r}180 \quad 00 \quad 03.64 \\
\text { Spherical excess_. } 0.90\end{array}$ & & 180 & 00 & $\begin{array}{l}00.90 \\
-0.90\end{array}$ \\
\hline & & Error_...... +2.74 & & & & \\
\hline
\end{tabular}

Angle equations

To select the sines for the side equation: Consider the figure as a pyramid with vertex (the pole) at 1 ; by redrawing the figure with the line 4-2 dotted and the triangle 1-3-4 shaded, it will appear to the eye as such a pyramid. Select for the first set of angles for the side equations those opening to the front in going around the base of the pyramid from 2 to 3 to 4 to 2 ; for future reference mark them with solid 
arcs of circles; the remaining angles around the base make up the other set and may be marked with dotted arcs. The pole should be selected so that the two smallest angles will be used in the equations. Find the sines for each set of angles, recording also the differences for $1^{\prime \prime}$ for each; call the first set of sines plus and the second set minus, find the difference between them, and give it the sign of the greater.

Side equations

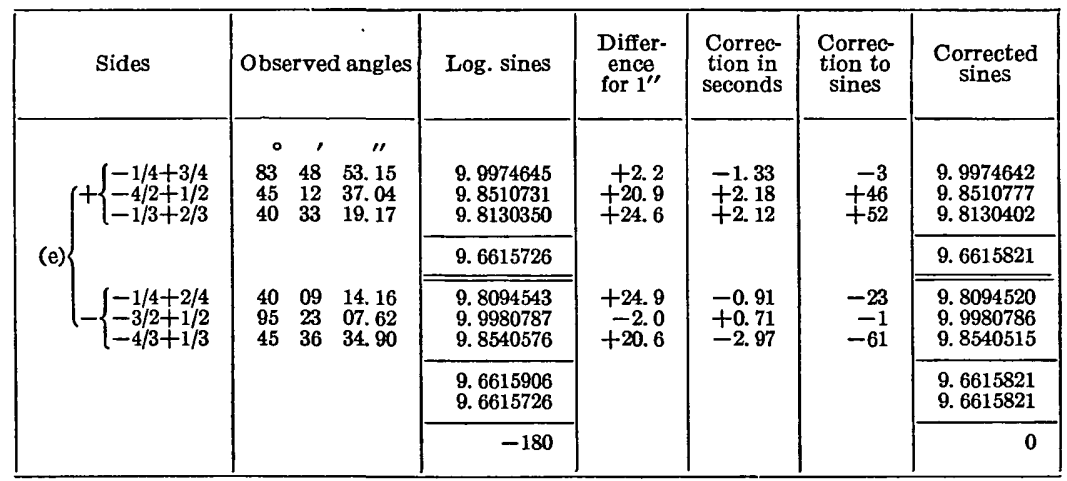

Equations of condition are now made up as follows: For triangle (a), equation (f), error equals $-3.45^{\prime \prime}$; this is made up of the errors in the azimuth or direction of the sides $-1 / 4+3 / 4-4 / 2+1 / 2-1 / 3+2 / 3$, six in all. In like manner form equations $(\mathrm{g})$ and $(\mathrm{h})$. The side equation (i) is made up as follows: The error of the sines, being the difference between the two sets, is -180 . To correct the sines changes in seconds to be found for the angles must be multiplied by the differences for 1 second in column 4 of (e) for the given angle; hence for the first sine this will be +2.2 multiplied by the corrections to be given the directions $-1 / 4$ and $+3 / 4$, or if expressed in a simple form it will be $-2.21 / 4+2.23 / 4$. Treat each side and difference for 1 second in like manner, noting, however, that for the second set of sines, which is considered negative, each sign given for the side will be reversed-for example, the first pair is written $+24.91 / 4-24.9$ $2 / 4$. It will be noticed that in the first form of (i) as written, $1 / 2$ appears twice with like signs, $1 / 4$ appears twice with unlike signs; combine like terms algebraically, thus reducing the equations to the second form of (i). For the convenience of the computer and in order to avoid the handling of large numbers, equation (i) has been divided through by 100 , which is equivalent to taking as the unit the fifth place of decimals of the logarithms.

(f) $0=-3.45-1 / 3+2 / 3-2 / 1+3 / 1-3 / 2+1 / 2$.

(g) $0=-1.49-1 / 4+2 / 4-2 / 1+4 / 1-4 / 2+1 / 2$.

(h) $0=+4.70-4 / 3+1 / 3-1 / 4+3 / 4-3 / 1+4 / 1$.

(i) $0=-1.80-0.0221 / 4+0.0223 / 4-0.2094 / 2+0.2091 / 2-0.2461 / 3+0.2462 / 3$ $-(-0.2491 / 4+0.2492 / 4+0.0203 / 2-0.0201 / 2-0.2064 / 3+0.2061 / 3)$. 
Combining like terms and changing all signs within the parentheses reduces equation (i) to the following form:

(i) $0=-1.80+0.2271 / 4+0.0223 / 4-0.2094 / 2+0.2291 / 2-0.4521 / 3+0.2462 / 3$ $-0.2492 / 4-0.0203 / 2+0.2064 / 3$.

There are now four equations to be solved and 12 unknown quantities; the latter are combined and reduced to four by means of correlates. In the following table column (j) contains the designations of the sides or directions for which corrections are required. Column (k) contains on the proper lines the algebraic coefficients for the sides from equation ( $f$ ); for example, $-1 / 3$, considered as a quantity, might be written $-1(1 / 3)$, and $+2 / 3$ in like manner written $+1(2 / 3) ;-1$ and +1 are therefore the entries for column $(\mathrm{k})$, lines $1 / 3$ and $2 / 3$.

Correlates

\begin{tabular}{|c|c|c|c|c|c|c|c|c|c|c|}
\hline (j) & (k) & (1) & (m) & (n) & \multicolumn{4}{|c|}{ Correlates after $\begin{array}{l}\text { substituting computed } \\
\text { values }\end{array}$} & \multirow{2}{*}{$\begin{array}{l}\text { Correc- } \\
\text { tions }\end{array}$} & \multirow{2}{*}{ Sides } \\
\hline Sides & 1 & 2 & 3 & 4 & $\begin{array}{ll}1 \\
-0.314\end{array}$ & $\begin{array}{l}2 \\
+0.590\end{array}$ & $\begin{array}{l}3 \\
-0.651\end{array}$ & $\begin{array}{l}4 \\
+3.010\end{array}$ & & \\
\hline $\begin{array}{l}2 / 1 \\
3 / 1\end{array}$ & $\begin{array}{r}-1 \\
1\end{array}$ & -1 & -1 & & $\begin{array}{l}+0.314 \\
-.314\end{array}$ & -0.590 & +0.651 & & $\begin{array}{r}-0.276 \\
+.337\end{array}$ & $\begin{array}{l}2 / 1 \\
3 / 1\end{array}$ \\
\hline $\begin{array}{l}4 / 1 \\
1 / 2\end{array}$ & & & & +0.229 & -314 & $\begin{array}{r}+\quad 590 \\
+\quad 590\end{array}$ & -.651 & +0.689 & $\begin{array}{r}1.061 \\
+.965\end{array}$ & $\begin{array}{l}4 / 1 \\
1 / 2\end{array}$ \\
\hline $\begin{array}{l}3 / 2 \\
4 / 2\end{array}$ & -1 & -1 & & $\begin{array}{l}-.020 \\
-.209\end{array}$ & +.314 & $=590$ & $\cdots$ & $\begin{array}{l}-.060 \\
-.629\end{array}$ & $\begin{array}{l}+.254 \\
-1.219\end{array}$ & $\begin{array}{l}3 / 2 \\
4 / 2\end{array}$ \\
\hline $1 / 3$ & -1 & $\ldots$ & $i^{-}$ & -.452 & +.314 & . & -.651 & -1.361 & $\begin{array}{l}-1.698 \\
-1.28\end{array}$ & 1/3 \\
\hline $\begin{array}{l}2 / 3 \\
4 / 3\end{array}$ & & & -1 & $\begin{array}{l}+.246 \\
+\quad 206\end{array}$ & -.314 & & +651 & $\begin{array}{l}+.740 \\
+.620\end{array}$ & $\begin{array}{r}+.426 \\
+1.271\end{array}$ & $\begin{array}{l}2 / 3 \\
4 / 3\end{array}$ \\
\hline $1 / 4$ & $\cdots$ & -1 & -1 & +.227 & 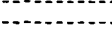 & -590 & +.651 & $\begin{array}{r}+683 \\
+.680\end{array}$ & +.744 & $1 / 4$ \\
\hline $\begin{array}{l}3 / 4 \\
3 / 4\end{array}$ & & & $i$ & +.022 & & & -.651 & +.066 & $\begin{array}{l}-.1585 \\
-.585\end{array}$ & $\begin{array}{l}2 / 2 \\
3 / 4\end{array}$ \\
\hline
\end{tabular}

Normal equations are formed from the table of correlates as follows: Column 1, line 1, of (o) (p. 75) contains the sum of the squares of each quantity in column ( $\mathrm{k}$ ). Column 2, lines 1 and 2, contains, first, the sum of the products of each quantity in column (k) by corresponding quantities in column (1); second, the sum of the squares of each quantity in column (l). Column 3, lines 1, 2, and 3 , contains the sum of the products of $(k)$ by $(m),(l)$ by $(m)$, and $(m)$ by $(\mathrm{m})$ (the squares). Column 4 is made up in the same manner, using the quantities and signs as given. If columns 1,2 , and 3 are completely filled out by products found as indicated above, it will be found that the quantities from +6.000 down the column are the same as those from +6.000 along the lines to the right to column 4 . But as the former are not needed in the solution they may be omitted; when retained, the equations in full will be as follows, the second member of each equation being zero: 
(o) Normal equations

\begin{tabular}{|c|c|c|c|c|}
\hline 1 & 2 & 3 & 4 & $\underset{\text { term }}{\text { Absolute }}$ \\
\hline $\begin{array}{l}+6.000 \\
+2.000 \\
-2.000 \\
+0.947\end{array}$ & $\begin{array}{l}+2.000 \\
+6.000 \\
+2.000 \\
-0.038\end{array}$ & $\begin{array}{r}-2.000 \\
+2.000 \\
+6.000 \\
-0.863\end{array}$ & \begin{tabular}{c}
+0.947 \\
-.038 \\
\hdashline .863 \\
+.51779
\end{tabular} & $\begin{array}{l}-3.450 \\
-1.490 \\
+4.700 \\
-1.800\end{array}$ \\
\hline
\end{tabular}

These are ordinary algebraic equations which may be solved by the usual rules of algebra, but, as the solution of 10,15 , or more equations is often required in Geological Survey work, the process should be conducted systematically as shown.

Solution of normal equations

(p)

\begin{tabular}{|c|c|c|c|c|c|}
\hline & 1 & 2 & 3 & 4 & $\begin{array}{c}\text { Absolute } \\
\text { term }\end{array}$ \\
\hline $\begin{array}{l}\left(\mathrm{p}_{1}\right) \\
\left(\mathrm{p}_{2}\right)\end{array}$ & $\begin{array}{l}+6.000 \\
(-.1667)\end{array}$ & $\begin{array}{r}+2.000 \\
-.333\end{array}$ & $\begin{array}{r}-2.000 \\
+.333\end{array}$ & $\begin{array}{r}+0.9470 \\
-.1578\end{array}$ & $\begin{array}{r}-3.450 \\
+.575\end{array}$ \\
\hline $\begin{array}{l}\left(\mathrm{p}_{3}\right) \\
\left(\mathrm{p}_{4}\right)\end{array}$ & & $\begin{array}{l}+5.333 \\
(-.1875)\end{array}$ & $\begin{array}{r}+2.667 \\
-.500\end{array}$ & $\begin{array}{l}-.3537 \\
+.0663\end{array}$ & $\begin{array}{l}-.340 \\
+.064\end{array}$ \\
\hline $\begin{array}{l}\left(\mathrm{p}_{5}\right) \\
\left(\mathrm{p}_{6}\right)\end{array}$ & & 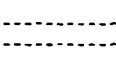 & $\begin{array}{l}+4.000 \\
(-.250)\end{array}$ & $\begin{array}{r}-.3705 \\
+.0926\end{array}$ & $\begin{array}{r}+3.720 \\
-.930\end{array}$ \\
\hline $\begin{array}{l}\left(\mathrm{p}_{7}\right) \\
\left(\mathrm{p}_{8}\right)\end{array}$ & & & & $\begin{array}{c}+.31060 \\
(-3.2196)\end{array}$ & $\begin{array}{r}-.935 \\
+3.010\end{array}$ \\
\hline
\end{tabular}

(q)

\begin{tabular}{|c|c|c|c|c|}
\hline & 2 & 3 & 4 & $\underset{\text { term }}{\text { A bsolute }}$ \\
\hline $\begin{array}{l}\left(q_{1}\right) \\
\left(q_{2}\right)\end{array}$ & $\begin{array}{l}+6.000 \\
-.667\end{array}$ & $\begin{array}{r}+2.000 \\
+.667\end{array}$ & $\begin{array}{r}-0.0380 \\
-.3157\end{array}$ & $\begin{array}{r}-1.490 \\
+1.150\end{array}$ \\
\hline $\begin{array}{l}\left(\mathrm{q}_{3}\right) \\
\left(\begin{array}{l}q_{4} \\
\mathrm{q}_{5}\end{array}\right)\end{array}$ & & $\begin{array}{r}+6.000 \\
-1.667 \\
-1.333\end{array}$ & $\begin{array}{r}-.8630 \\
+.3157 \\
+.1768\end{array}$ & $\begin{array}{r}+4.700 \\
-1.150 \\
+.170\end{array}$ \\
\hline $\begin{array}{l}\left(\mathrm{q}_{6}\right) \\
\left(\mathrm{q}_{7}\right)\end{array}$ & & & $\begin{array}{l}+.51779 \\
\pm .0149447 \\
-.023450\end{array}$ & $\begin{array}{r}-1.800 \\
+. .544 \\
-.023\end{array}$ \\
\hline (q0) & & & -.034318 & +.344 \\
\hline
\end{tabular}

(r)

\begin{tabular}{|c|c|c|c|c|}
\hline & 1 & 2 & 3 & 4 \\
\hline $\begin{array}{l}\left(r_{1}\right) \\
\left(r_{2}\right)\end{array}$ & $\begin{array}{r}+0.575 \\
-.475\end{array}$ & $\begin{array}{r}+0.064 \\
+.200\end{array}$ & $\begin{array}{r}-0.930 \\
+.279\end{array}$ & \multirow[t]{4}{*}{+3.010} \\
\hline$\left(r_{3}\right)$ & -.217 & +.326 & \multirow[t]{3}{*}{-.651} & \\
\hline$\left(r_{1}\right)$ & -.197 & \multirow[t]{2}{*}{+.590} & & \\
\hline$\left(\mathrm{r}_{8}\right)$ & -.314 & & & \\
\hline
\end{tabular}


The first normal equation is written in full on line $\left(p_{1}\right)$; parts of the other equations are written on lines $\left(q_{1}\right),\left(q_{3}\right)$, and $\left(q_{6}\right)$. The reciprocal from Barlow's tables of the first quantity $(+6.000$, line $\left(p_{1}\right)$, column 1$)$, is placed in parentheses, line $\left(p_{2}\right)$. The product of this reciprocal $(0.1667)$ by the quantitites on line $\left(p_{1}\right)$, columns 2,3 , and 4, and absolute are written immediately under each in turn; the quantity +0.333 (line $\left(p_{2}\right)$, column 2 ) is now used as a multiplier for line $\left(p_{1}\right)$ (omitting column 1 ), and the products are placed in columns $2,3,4$, and absolute, line $\left(\mathrm{q}_{2}\right)$; in like manner the quantities -0.333 (line $\left(p_{2}\right)$, column 3 ) and -0.1578 (column 4 ) are used as multipliers and the products written on lines $\left(q_{4}\right)$ and $\left(q_{7}\right)$. The algebraic sums of lines $\left(q_{1}\right)$ and $\left(q_{2}\right)$ are now written on line $\left(p_{3}\right)$, which is then used as if it were an original equation. The reciprocal of +5.333 is found and used as a multiplier as before, and the products are written on line $\left(p_{4}\right)$. The next products are wtitten on lines $\left(q_{5}\right)$ and $\left(q_{8}\right)$. The sums of each column of lines $\left(q_{3}\right),\left(q_{4}\right)$, and $\left(q_{5}\right)$ is carried over to $\left(p_{5}\right)$. The process is repeated for each equation until finally the product +3.010 is found, which is the value for unknown quantity numbered 4 . This value and also the quantitites in the column of absolute terms, lines $\left(p_{6}\right),\left(p_{4}\right)$, and $\left(p_{5}\right)$, are copied in the table $(r)$, line $\left(r_{1}\right)$. With +3.010 as a multiplier products of each quantity in column 4 , lines $\left(p_{6}\right),\left(p_{4}\right)$, and $\left(p_{2}\right)$, are found and written on line $\left(\mathrm{r}_{2}\right)$, columns 3,2 , and 1 . Column 3 or $(\mathrm{r})$ is then summed and the result $(-0.651)$ is the value of unknown quantity numbered 3. This is used as a multiplier and products found with quantities from columns 3 and 2 , lines $\left(p_{4}\right)$ and $\left(p_{2}\right)$, and in like manner values for unknown quantities numbered 2 and 1 are found.

The solution of the normal equations and the values found for the unknown quantities may be checked by substituting in the full equations (p. 75).

The next step in the adjustment is to substitute the values for the four unknown quantities in the table of correlates (p. 74) and to find the correction for each side. The method of doing this can be easily seen by following the process through the right-hand half of that table. For convenience, the value found for each unknown quantity is written at the head of columns 1,2,3, and 4. Each of these in turn is multiplied by quantities in columns $1,2,3$, and 4 of the lefthand part of the table and the products are placed in the right-hand part on the same line with the multiplicand. The final correction for any side is then the algebraic sum of the quantities, which are on line with the side number in columns $1,2,3$, and 4 (at the right side of the table). Thus the correction $2 / 1$ is made up of +0.314 $-0.590=-0.276$; this is the correction in seconds to the side. The correction for any angle, then, is the difference between the cor- 
rections for the two sides bounding it. For example: Angle at Elk, triangle (a), is:

- correction $1 / 3=+1.698$

. + correction $2 / 3=+.426$

$+2.124$

The correction for any sine is the correction for the corresponding angle multiplied by the difference for $1^{\prime \prime}$ in the sine.

It is desirable to have triangles close without errors greater than a tenth of a second and to have side equations close to the sixth place of the logarithm, but unless the normal equations are carried to three or four decimal places there will possibly be residual errors of two or three hundredths in some triangle closures. It is, however, considered allowable in Geological Survey work to make arbitrary changes of not over $\pm 0.03^{\prime \prime}$ in angles in order to obtain consistent results.

The figures for adjustment will generally be larger than quadrilaterals, though they may be made up of quadrilaterals or triangles which do not overlap and are therefore independent each of the other. When they do overlap select for the first pyramid group (p. 70) the one which takes in the largest number of triangles and set down (according to the formula on p. 72) the number of triangle equations required to adjust it completely, remembering that the triangles used must always cover the whole area once but not twice. For the second group set down the number of triangle equations required by the rule as if they were from an independent pyramid group, but omit from those selected all which would be adjusted in or by the first group, the vertex of the pyramid being so situated that a base triangle will not be included in a former group. In other words, as group by group is added to the first find for each a single side equation and as many additional angle equations as are required, including in the number all triangles adjusted by a previous group excluding those which appear in each or which would appear in each if the vertex of the pyramid were taken in a different place.

In any figure in which each station is sighted from every other one no attention need be paid to the selection of triangles for use in the adjustment; they may be taken at random, provided the number required by the formula is used.

In order to adjust an extensive triangulation scheme, the strongest groups are adjusted first; then if lines or triangles in them form parts of other groups, their first adjusted values are given infinite weights and thus left unchanged.

In connecting new groups of triangles with those previously adjusted, if more than a single adjusted line is used a condition must be introduced fixing the relative length of the adjusted lines. For 
example: Let the solid lines in Figure 2 represent an adjusted group and the dotted lines part of a new group of triangles to be adjusted. It is evident that the distance $a c$ and the angle $a b c$ are fixed by the completed adjustment; therefore in adjusting the new work a side equation must be used in order to maintain the relative length of the lines $a b$ and $b c$. This may be taken from the quadrilateral $a d c e$ with the central point $b$, infinite weight being given to the five adjusted lines.

The accuracy of figure adjustments will be increased if the sines of the smallest angles are used in forming the equations and if each

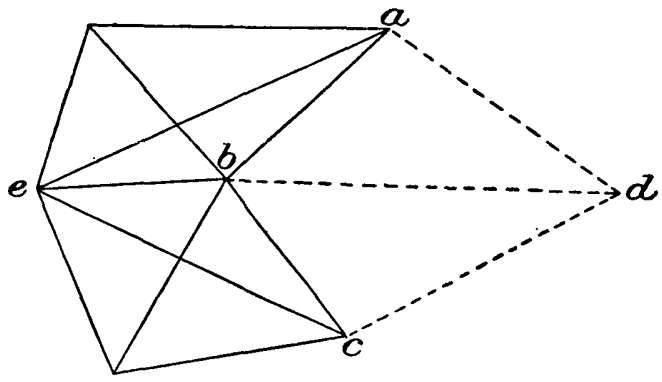

Figure 2.-Condition to be introduced in connecting new triangles to those previously adjusted figure used covers the largest possible area; but on the other hand labor will be saved if as few angles as possible are involved. These conditions appear when two figures overlap; in such cases a sum angle can be used in adjusting one figure, with a saving of labor, but unless all the triangles are of good shape it is better to

take the triangles which cover the largest area. Whether the slight increase in accuracy justifies the extra labor involved depends on the quality of the work.

The angles to be used depend on the position taken for the pole of the assumed pyramid.

\section{WEIGHTED OBSERVATIONS}

If the field notes show that certain angle measures are incomplete or uncertain it is generally advisable to introduce weights. These may be in the form of fractions or whole numbers, but in assigning them the field observations and records alone should be considered, not triangle closures. An infinite weight is given when it is desired to hold the value for a direction, as when it is taken from a previously adjusted figure. A weight of $\infty$ for a side reduces all correlatetable products for it to 0 -in other words, eliminates its effect on the normal equations.

Weights are used only in the table of correlates on page 79 . As an example of their use let weights be assumed for directions in the table of correlates as follows:

The rule for forming normal equations from weighted correlates is that each product for a given side is to be divided by the weight for that side before combining it to form a term in the equation. 
For example: The first term in equation 1 is made up as follows from column $t$ of the correlates:

Side $2 / 1(-1)(-1) \div$ weight $2=+0.500$

Side $3 / 1(+1)(+1) \div$ weight $1=+1.000$

Side $1 / 2(+1)(+1) \div$ weight $2=+0.500$

Side $3 / 2(-1)(-1) \div$ weight $3=+0.333$

Side $1 / 3(-1)(-1) \div$ weight $1=+1.000$

Side $2 / 3(+1)(+1) \div$ weight $\frac{1}{2}=+2.000$

$$
+5.333
$$

The sum of these quantities, +5.333 , is the coefficient of the first term. The fourth term of equation 1 is

Side $1 / 2(+1)(+0.229) \div$ weight $2=+0.1145$

Side $3 / 2(-1)(-0.020) \div$ weight $3=+0.0067$

Side $1 / 3(-1)(-0.452) \div$ weight $1=+0.4520$

Side $2 / 3(+1)(+0.246) \div$ weight $\frac{1}{2}=+0.4920$

Combining these quantities gives +1.0652 , which is the coefficient of the term desired Each other term of the normal equation is found in a similar manner.

These equations after solving by the usual methods give the values at the head of columns 1, 2, 3, and 4 in the right-hand part of the following table of correlates. These values after multiplying by the quantities in columns $t, u, v$, and $w$ are placed in their appropriate spaces and the sum for each line found as described on page 76. Each sum thus found for a side is then divided by the weight for the side, the quotient being the correction for the side, and the corrections thus found, if applied to the triangles (p. 72) and the side equation (p. 75), will make a complete adjustment for the figure.

\section{Correlates for weighted equations}

\begin{tabular}{|c|c|c|c|c|c|c|c|c|c|c|c|}
\hline Sides & Weights & $\frac{t}{1}$ & $\mathbf{u}$ & $\mathbf{v}$ & w & $\left(\begin{array}{c}1 \\
(-0.415)\end{array}\right.$ & $\begin{array}{c}2 \\
(+0.703)\end{array}$ & $\begin{array}{c}3 \\
(-0.756)\end{array}$ & $\left(\begin{array}{c}4 \\
(+3.236)\end{array}\right.$ & Sums & $\begin{array}{l}\text { Sums } \\
\text { divided } \\
\text { by } \\
\text { weights }\end{array}$ \\
\hline $\begin{array}{l}2 / 1 \\
3 / 1 \\
4 / 1 \\
1 / 2 \\
3 / 2 \\
4 / 2 \\
1 / 3 \\
2 / 3 \\
4 / 3 \\
1 / 4 \\
2 / 4 \\
3 / 4\end{array}$ & $\begin{array}{l}2 \\
1 \\
1 \\
2 \\
3 \\
1 \\
1 \\
\\
\frac{3}{2} \\
2 \\
1 \\
1\end{array}$ & $\begin{array}{r}-1 \\
1 \\
\hdashline 1 \\
-1 \\
\hdashline-1 \\
1 \\
\hdashline- \\
\hdashline- \\
\hdashline-\end{array}$ & $\begin{array}{r}-1 \\
\hdashline 1 \\
1 \\
-1 \\
-1 \\
\hdashline- \\
\hdashline-1 \\
1 \\
\hdashline\end{array}$ & $\begin{array}{r}-1 \\
1 \\
\hdashline \\
\hdashline \\
\hdashline 1 \\
\hdashline-1 \\
-1 \\
\hdashline 1\end{array}$ & $\begin{array}{r}+0.229 \\
-.020 \\
-.209 \\
-.452 \\
+.246 \\
+.206 \\
+.227 \\
+.249 \\
+.022\end{array}$ & \begin{tabular}{r}
+0.415 \\
-.415 \\
\hdashline .415 \\
+.415 \\
\hdashline .415 \\
-.415
\end{tabular} & $\begin{array}{r}-0.703 \\
+.703 \\
+.703 \\
-.703\end{array}$ & $\begin{array}{r}-.756 \\
+.756 \\
+.756 \\
.756\end{array}$ & $\begin{array}{r}+0.741 \\
-.065 \\
-.676 \\
-1.463 \\
+.797 \\
+.666 \\
+.735 \\
-.806 \\
+.071\end{array}$ & $\begin{array}{r}-0.288 \\
+.341 \\
+.053 \\
+1.029 \\
+.350 \\
-1.379 \\
-1.804 \\
+.382 \\
+1.422 \\
+.788 \\
-.103 \\
-.685\end{array}$ & $\begin{array}{r}-0.144 \\
+.341 \\
-.053 \\
+.514 \\
+.117 \\
-1.379 \\
-1.804 \\
+.764 \\
+1.422 \\
+.394 \\
-.103 \\
-.685\end{array}$ \\
\hline
\end{tabular}


Normal equations

\begin{tabular}{|c|c|c|c|c|}
\hline 1 & 2 & 3 & 4 & Absolute \\
\hline $\begin{array}{l}+6.939 \\
+1.000 \\
-2.000 \\
+1.0652\end{array}$ & $\begin{array}{r}+1.000 \\
+4.500 \\
+1.500 \\
-.039\end{array}$ & $\begin{array}{r}-2.000 \\
+1.500 \\
+5.600 \\
-.750\end{array}$ & $\begin{array}{l}+1.0652 \\
=.039 \\
-.750 \\
+.526055\end{array}$ & $\begin{array}{l}-3.450 \\
-1.490 \\
+4.700 \\
-1.800\end{array}$ \\
\hline
\end{tabular}

In the solutions of the normal equations on page 75 no method was shown for checking the work before the final values of the unknown had been found and substituted in the full equations. There is a simple method for checking a solution frequently, and as it involves but little extra labor it should be adopted when a large number of simultaneous equations are to be solved. The check requires an added term for each equation, the numerical value of which is the algebraic sum of all the coefficients and the absolute term of each full normal equation. The check numbers should be given a sign opposite to that of the sum, so that the equations will still have the form of $(a)+(b)+$ etc. $=0$.

In the following solution the check is used; the solution differs slightly in form of arrangement from that shown on page 75 and is in some respects simpler.

The check column is numbered 6 ; the first term, line (a), is the algebraic sum of each quantity on line (a) with the opposite sign; similarly lines (c), (g), and (l) contain check numbers found from the sum of the quantities in each of the full equations; but as all the terms of each equation are not written down they may be found, because of the symmetry of the equations, from quantities given in other equations. For example, for equation 3 add together the quantities in column 3 of the normal equations (p. 75) and those on the third line: $-2.000+1.500+5.500-0.750+4.700=8.950$; hence -8.950 is the check number. The check numbers are to be treated in the solution as if they were absolute quantities.

For the first equation the reciprocal of the first coefficient (5.333) with its sign changed is -0.1875 ; this multiplied by each term of line (a) gives the quantities in line (b).

The quantity -0.1875 (column 2 , line $b$ ) is next taken as a multiplier for all the coefficients immediately above it and for others to the right on line (a), the products being written on line (d). 
Solution of equations, with check

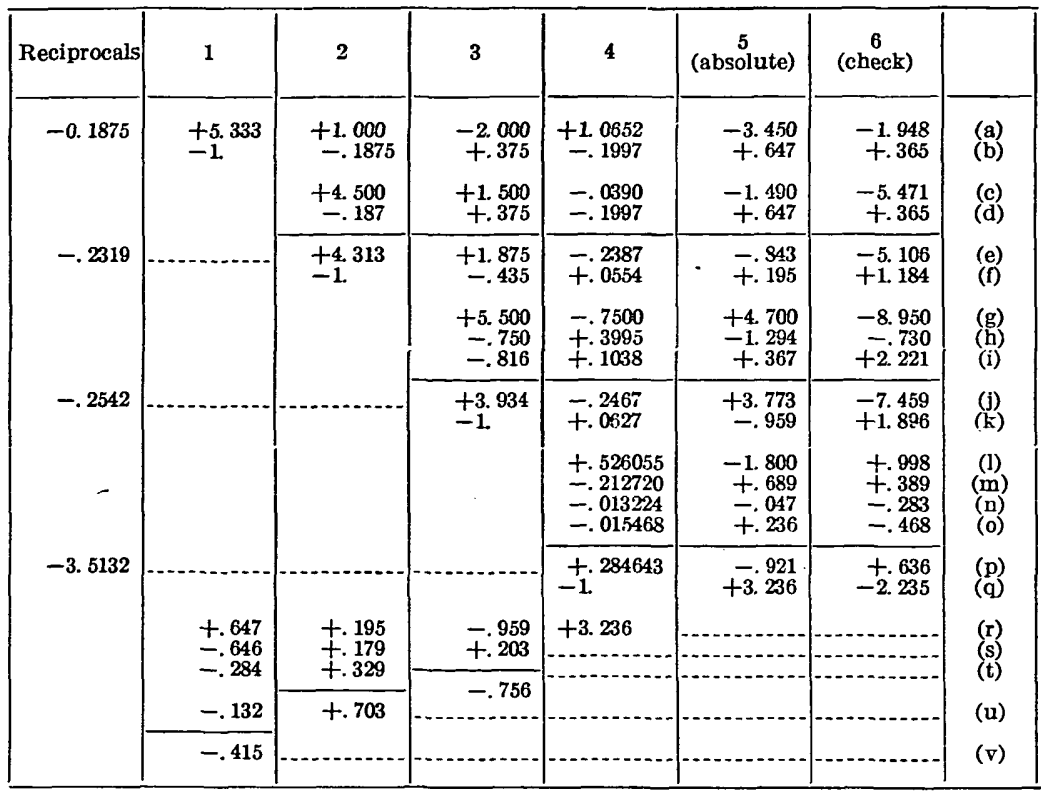

Products for equation 3 , witten on line (h), are found with the multiplier +0.375 and the quantities in columns $3,4,5$, and 6 , line (a). All the other numbers on line (b) for any set of equations except those in the absolute column 5 and the check column 6, are used as multipliers, and the products are written under the equations to which they belong. Lines (c) and (d) are next added algebraically and the sums written on line (e).

Line (e) now consists of a complete equation containing but three unknown quantities, an absolute term, and a check term, and the algebraic sum of all the quantities on the line should be zero, reasonable allowance being made for slight errors introduced from the dropping of decimal places beyond the fourth. This constitutes the first useful application of the check term.

The reciprocal of the first term in line (e) with sign changed is -0.2319 ; this multiplied by each quantity in line (e) gives the products on line (f); these also if combined algebraically should equal zero, and thus the work is again checked.

Products from multipliers for each unknown quantity ( -0.435 and +0.0554 ) are next found in the same manner as for lines (a) and (b) and written under the equations to which they belong (on lines (i) and $(m)$ in this example). The algebraic sum of each column under equation 3 is next to be found and written on line ( $j$ ). This is now a complete equation with two unknown quantities, and the sum for the whole line should equal 0 , this being the third use of the check 
term. This elimination process is repeated and the check applied until line (q) is reached, the absolute term then being the value of the fourth unknown. This value is written on line (r), column 4, and the absolute quantities from column 5, lines (k), (f), and (b), are written in columns 3,2 , and 1 , line $(r)$. The numerical value of number 4 is next to be multiplied by the coefficients of number 4 in column 4 , lines $(\mathrm{k}),(\mathrm{f})$, and (b), and the products written on line (s), columns 3,2 , and 1 , respectively. The sum of the quantities in lines ( $r$ ) and (s), column 3 , is -0.7560 , which is the value found for unknown number 3 , and this value substituted in column 3 gives products for line (s).

\section{ADJUSTING IINES TO UNOCCUPIED STATIONS}

An adjustment can be made for the three lines to an unoccupied station as follows: Correct the observed angles to the unoccupied point to agree with previously adjusted angles at each occupied station; then form a side equation, making the unoccupied station the pole of the pyramid, if thereby the small angles are used in making up the equations.

The swings for the lines to the unoccupied station, which will be the corrections desired, will be the products of the sine differences for $1^{\prime \prime}$ (coefficients of the sine equation) by the absolute term, divided by the sum of the squares of the former.

For each additional line more than three to the unoccupied station an additional side equation is required, all to be solved in the usual manner.

\section{COMPUTATION OF DISTANCE}

The computations of distance are to be made in book 9-901. The triangles are arranged in order from a given base or known side, one page or part of a page being taken for each new station. For each triangle the adjusted spherical angles and the spherical excess are given to hundredths of seconds.

Example of computation of distance

\begin{tabular}{|c|c|c|c|c|}
\hline Station & $\begin{array}{c}\text { Spherical } \\
\text { angle }\end{array}$ & $\begin{array}{l}\text { Spherical } \\
\text { excess }\end{array}$ & $\begin{array}{l}\text { Plane angle } \\
(9.8853615)\end{array}$ & $\begin{array}{l}\text { Log sines } \\
\text { and dis- } \\
\text { tances }\end{array}$ \\
\hline $\begin{array}{l}\text { Browning.- } \\
\text { Elk } \\
\text { Dick. }\end{array}$ & $\begin{array}{ccc}\circ & \prime & \prime \prime \\
50 & 10 & 29.11 \\
86 & 09 & 53.23 \\
43 & 39 & 38.56\end{array}$ & $\begin{array}{l}=0.30 \\
=.30 \\
-.30\end{array}$ & $\begin{array}{ccc}\circ & , & \prime \prime \\
50 & 10 & 28.81 \\
86 & 09 & 52.93 \\
43 & 39 & 38.26\end{array}$ & $\begin{array}{l}\text { 4. } 2984616 \\
0.1146385 \\
9.9990263 \\
\text { 9. } 8390917\end{array}$ \\
\hline $\begin{array}{l}\text { Miles, } 11.106 \ldots \ldots \\
\text { Miles, } 16.050 \ldots . . .\end{array}$ & $\begin{array}{lll}180 & 00 & 00.90 \\
\end{array}$ & Brov & $\begin{array}{l}18000 \quad 00.00 \\
\text { ing to Elk. } \\
\text { ing to Dick. }\end{array}$ & $\begin{array}{l}4.2521918 \\
4.4121264\end{array}$ \\
\hline
\end{tabular}


After adjustment of several overlapping figures has_been completed, it is occasionally necessary to find the length of some line joining two points which has not been included in the adjustment. Such lines may usually be computed by the formula for "two sides and the included angle." ${ }^{3}$

The rule for the solution of plane triangles for which the three angles and one side are given is that the sides are proportional to the sines of the opposite angles. By always arranging the angles in the form above suggested, with the new station first, the solution is made somewhat mechanical. The logarithms of the sines of plane angles are used; that for the angle at the new station from which distances are required to the other two stations is written immediately above the angle; its arithmetical complement (10 minus the sine) is written. to the right and on line with the angle. Each of the other sines is placed on line with the angle to which it relates. Immediately above the sines is written the logarithm of the distance in meters ${ }^{4}$ between the second and third stations in the triangle; in the example this is 4.2984616 for the line Elk to Dick.

To get the logarithm of the distance from the new station (Browning in the example) to one of the other stations, omit the sine opposite the latter and add together the remaining logarithms in the righthand column. The distance to thousandths of a mile for each computed line must be found and placed to the left of the names of the terminal stations. The work should be verified by comparing distances for each line that has been computed from two or more triangles.

\section{COMPUTATION OF GEODETIC COORDINATES}

For the computation of geodetic coordinates use book 9-902 and check results by computing each position from two stations which form a triangle with the new station. For convenience, only one of the computations is here given:

${ }^{3}$ U. S. Geol. Survey Bull. 650, p. 8, 1918.

4 Meters are used by the Geological Survey in all triangulation computations for the reason that the best obtainable geodetic factors are those prepared by the United States Coast and Geodetic Survey, which are metric. 


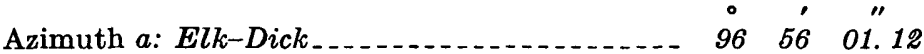

Spherical angle at $E l k \ldots \ldots$. 09 53. $23+$

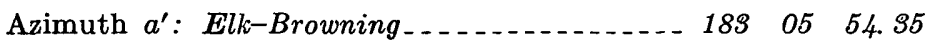

$\triangle \mathrm{a}+180^{\circ}$

$180 \quad 00 \quad 24.02$

Azimuth (a): Browning-Elk

$306 \quad 18.37$

LATITUDE

\begin{tabular}{|c|c|c|c|}
\hline & 。 & , & $\|$ \\
\hline$\phi_{\ldots} \ldots$ & 37 & 28 & 47.32 \\
\hline$\Delta \phi_{-} \ldots$ & & 9 & 38. $88(+)$ \\
\hline
\end{tabular}

Computation for latitude:

$\log s_{\ldots} \ldots \ldots-2.2521918$

$\log B \ldots \ldots .5110415$

$\log \cos a^{\prime} \ldots$ 9. $9993647(-)$

$\log (\mathrm{I}) \ldots \ldots$ 2. $7625980(-)$

$\log s^{2} \ldots \ldots .50438$

$\log C_{\ldots} \ldots \ldots 1.28943$

$\log \sin ^{2} a^{\prime} \ldots$ 7. 46561

$\log (\mathrm{II}) \ldots \ldots .25942$

$\log D_{\ldots} \ldots \ldots$ 2. 3771

$\log [\mathrm{I}+\mathrm{II}]^{2}-5.5252$

$\log ($ III) $\ldots . . \overline{7.9023}$

$\log E$

6. 0528

$\log s^{2} \sin ^{2} a^{\prime}-5.9700$

$\log (\mathrm{I}) \ldots \ldots$ 2. $7626(-)$

$\log (\mathrm{IV}) \ldots \overline{4.7854(-)}$

-IV_..... .000(-)

(I) ..... $578,893(-)$

(II) .... .002+

(III) $\ldots . .008+$

(IV) ... . .000(+)

$-\triangle \phi_{-} \ldots \overline{578.883(-)}$

$\triangle \phi_{-} \ldots \ldots .938 .88(+)$
Elk.

Browning.

$\triangle$ arc and sine

$(\log s) \ldots-.-06$

$(\log V) \ldots+00$

$-06$

LONGITUDE

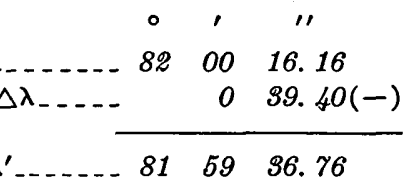

Computation for longitude:

$\log s_{\ldots} \ldots \ldots \ldots$. 2521918

$\log \sin a^{i} \ldots$ 8. $7328074(-)$

$\log A^{\prime}$

8. 5091777

$\log \sec \phi$

0. 1013532

$\Delta a$ and $s-1-=$

$(-6)$

$\log (V)$

1. $5955295(-)$

39. $403-$

$\Delta \boldsymbol{\lambda}$

39. $40-$

Computation for azimuth:

\begin{tabular}{|c|c|c|c|c|}
\hline$\circ$ & ' & $" 1$ & $\log (V)$ & 1. $595530(-)$ \\
\hline $\begin{array}{r}\phi 37 \\
\phi^{\prime} 37\end{array}$ & $\begin{array}{l}28 \\
38\end{array}$ & $\begin{array}{l}47.8 \\
26.9\end{array}$ & $\log \sin$ & 9. 785041 \\
\hline & 67 & 13. 5 & & 0.000000 \\
\hline 37 & 33 & 37.0 & $\log (V I)$ & 1. 3 \\
\hline
\end{tabular}

$-\triangle a_{-} \ldots \ldots$. $24^{\prime \prime} .02(-)$

$\triangle a_{-} \ldots \ldots \ldots 24^{\prime \prime} .02(+)$

Azimuth check.

[I+II] 578. 891

$\circ, 11$

$\log [\mathrm{I}+\mathrm{II}] \quad$ 2. 762598

$\begin{array}{lll}53 \quad 16 & 47.48\end{array}$

$\begin{array}{lll}3 & 06 & 18.97\end{array}$

$\log [\mathrm{I}+\mathrm{II}]^{2} \quad 5.525196$

$50 \quad 10 \quad 29.11$

Spherical angle

at Browning $50 \quad 10 \quad$ 29. 11

Computation of azimuth $a$, in book $A 1505$, page 26 .

Spherical angle and distance $s$, in book $A 1570$, page 32 .

Computed by $D . M . E$.

[Note.-The signs $(+)$ or $(-)$ placed after logarithms are the signs of the cosines or sines of the azimuth used in the computations.] 
In this example the azimuth, $96^{\circ} 56^{\prime} 01^{\prime \prime} .12$, is derived from a previous computation. The spherical angle is that at Elk from the adjusted figure. Whether to add or subtract this can be determined very easily by inspecting a plat of the stations, but when for one of the pair of computations the spherical angle is added, the other is always subtracted. The latitude and longitude at Elk are also derived from a previous computation. Logarithm $s$ is the logarithm of the distance in meters between Elk and Browning. The constants $B, C, D$, and $E$ are taken from "Geographic tables and formulas" 5 for the known latitude at Elk. Cosine $a^{\prime}$ and sine $a^{\prime}$ are functions of the azimuth Elk to Browning. The algebraic sign of each of these functions as fixed by trigonometric rules determines the sign. of the resulting quantity. The signs of (II) and (III) are always positive; that for (IV) is always opposite to that of (I). The constant $A^{\prime}$ and secant $\phi^{\prime}$ in the longitudinal computation are for the new latitude, which requires that the latitude computation be made first. These two factors will be the same for each of the pair of computations for the new position. For short lines, corrections (III) and (IV) will generally be less than $0.01^{\prime \prime}$ and may be neglected.

When the logarithm of distance $s$ in meters exceeds 4.0000000 , a correction will usually be required for logarithm (V) for the difference between the arc and sine. The constants for computing this correction are given on page 292 of "Geographic tables and formulas," 6 the arguments being $\log$ distance $s$ and $\log (\mathrm{V})$. The difference between the values found is to be applied, according to the sign of the greater, to $\log (\mathrm{V})$ before finding the value of the latter in seconds.

Six places of decimals will usually give sufficient accuracy for $\log (\mathrm{VI})$. The logarithm of secant $\left(\frac{\phi \triangle}{2}\right)$ may be taken from page 291 of "Geographic tables and formulas." When log (V) is large, say over 3.5000000 , a correction in seconds ${ }^{6}$ will be needed for $\triangle a$ expressed by the factor $(\Delta \lambda)^{3} \mathrm{~F}$. The logarithm of $(\mathrm{V})$ is multiplied by 3 and added to the logarithm of $F$, which is given in the tables; the value in seconds for the resulting logarithm is always to be added to the previously found value in seconds for (VI).

The latitudes and longitudes for each point thus computed in pairs should agree within one or two one-hundredths of a second.

The difference between the two reverse azimuths should also agree with the corresponding adjusted spherical angle within one or two one-hundredths of a second.

The formulas for finding azimuth and distance between points whose latitude and longitude are known and the form for 3-point computations are given in "Geographic tables and formulas." Special blanks for 3-point work may be procured by application to the Washington office. 


\section{TABULATION OF RESULTS}

The final step in the computation of triangulation is the tabulation of the results. A printed blank is used; on it is written the name of the station, the State and county in which the station is situated, the kind of signal and the center mark used, a full description of the station (see p. 62), the latitude and longitude, the azimuth, the back azimuth, and the logarithms of distances in meters and corresponding distances in miles to all other stations from which it is visible; also a statement regarding the datum on which positions are based. Whenever possible this should be the North American datum (formerly known as the United States standard datum).

\section{SUGGESTIONS TO COMPUTERS}

Do not crowd your work; paper is comparatively cheap.

Do your work in a systematic manner. If it permits tabular arrangement, always use the forms approved by other computers unless you can convince them that yours are better. The survey has printed forms for many purposes; these should be used whenever possible, for by their use the work is made more mechanical, and the more mechanically the work is done the less chance there is for error.

A computer who is inexperienced or out of practice should check his work in every way possible. He should check logarithms either of numbers or of circular functions by using first a tabular value for a quantity less than the given one and then a greater tabular value, so that the differences in one case may be added and in the other subtracted. This operation may be reversed when the logarithm is given and numbers or angles are required.

Many errors are made by taking out the first three figures of a logarithm from the wrong line of a seven-place table where a dash over the fourth figure indicates that the first three should come from a lower line.

As the algebraic signs of cosines and sines are so frequently required, the rules governing them should be firmly fixed in the mind; as an aid to this remember the general rule that distances measured upward or to the right on the conventional plat of the quadrants of the circle are considered positive, and others negative. The wrong use of signs is a very common source of error.

Where the function of an angle over $90^{\circ}$ is desired, instead of subtracting $90^{\circ}$ or $270^{\circ}$ from the angle to find the argument, add the figures in the tens and hundreds of degrees places together and prefix the sum to the unit degree figure, dropping the sum if it is 9. Thus $121^{\circ}$ gives $1+2=3$, and $31^{\circ}$ is the argument; $184^{\circ}$ gives $1+8=9$, drop it, leaving $4^{\circ}$ for the argument; $290^{\circ}$ gives $9+2=11$, 
drop 9 from the 11 or add the two figures a second time, giving an argument of $20^{\circ}$.

Each step in a long computation, if it is not at once automatically checked, should be checked by repeating the computation.

Check the copying of angles, distances, etc., taken from adjusted results for use in new computations; also check figures carried from page to page.

Gross errors are sometimes made by using the sine.when a cosine is required, or by writing a product in the wrong column, as east for west, in primary-traverse computations.

Placing the decimal point in the wrong place is a common mistake. This may in many cases be corrected by a mere inspection of the quantity to see whether it appears of proper value.

Good judgment should be exercised in the degree of accuracy sought for a given result. For the preliminary computation of geographic positions, for example, six-place logarithms will suffice; these can be taken from a seven-place table with only a rough interpolation. A four-place logarithm can often be used to advantage. The accuracy of the results obtained should equal the requirements; more than this involves a waste of time.

The foot, yard, and mile are the units adopted for all Geological Survey field work, but for geodetic computations meters are used. The best conversion tables for metric and English measures are those published by the Bureau of Standards. In using these tables all changes from one system to another should be checked by reversing the operation. The logarithms for the interchange of these measures are given in "Geographic tables and formulas," page 364.

When computers are duplicating work and a difference is found, each should recompute the result before correcting either, as errors have frequently been made by changing the correct figures.

When two persons are comparing a copy with the original if the reader occasionally calls out a wrong figure or word intentionally and notes whether the error is caught up, it tends to keep the listener more intent on the work. 
